\title{
Assessment of the Cumulative Effects of Restoration Activities on Water Quality in Tampa Bay, Florida
}

\author{
Marcus W. Beck ${ }^{1} \cdot$ Edward T. Sherwood $^{2} \cdot$ Jessica Renee Henkel ${ }^{3} \cdot$ Kirsten Dorans $^{4} \cdot$ Kathryn Ireland $^{5} \cdot$ Patricia Varela $^{6}$
}

Received: 10 April 2019 / Revised: 13 June 2019 / Accepted: 26 July 2019 / Published online: 5 August 2019

(C) The Author(s) 2019

\begin{abstract}
Habitat and water quality restoration projects are commonly used to enhance coastal resources or mitigate the negative impacts of water quality stressors. Significant resources have been expended for restoration projects, yet much less attention has focused on evaluating broad regional outcomes beyond site-specific assessments. This study presents an empirical framework to evaluate multiple datasets in the Tampa Bay area (Florida, USA) to identify (1) the types of restoration projects that have produced the greatest improvements in water quality and (2) time frames over which different projects may produce water quality benefits. Information on the location and date of completion of 887 restoration projects from 1971 to 2017 were spatially and temporally matched with water quality records at each of the 45 long-term monitoring stations in Tampa Bay. The underlying assumption was that the developed framework could identify differences in water quality changes between types of restoration projects based on aggregate estimates of chlorophyll-a concentrations before and after the completion of one to many projects. Water infrastructure projects to control point source nutrient loading into the Bay were associated with the highest likelihood of chlorophylla reduction, particularly for projects occurring prior to 1995 . Habitat restoration projects were also associated with reductions in chlorophyll-a, although the likelihood of reductions from the cumulative effects of these projects were less than those from infrastructure improvements alone. The framework is sufficiently flexible for application to different spatiotemporal contexts and could be used to develop reasonable expectations for implementation of future water quality restoration activities throughout the Gulf of Mexico.
\end{abstract}

Keywords Chlorophyll $\cdot$ Long-term monitoring $\cdot$ Restoration $\cdot$ Tampa Bay $\cdot$ Trends

\section{Introduction}

Despite considerable investments over the last four decades in coastal and estuarine ecosystem restoration (Diefenderfer et al. 2016), numerous challenges still impede comprehensive

Communicated by Nathan Waltham

Marcus W. Beck

marcusb@sccwrp.org

Edward T. Sherwood

esherwood@tbep.org

Jessica Renee Henkel

jessica.henkel@restorethegulf.gov

Kirsten Dorans

kdorans@tulane.edu

Kathryn Ireland

kathryn.b.ireland@gmail.com success. In the Gulf of Mexico (GOM), chronic and discrete drivers contribute to the difficulty in restoring and managing coastal ecosystems. For example, the synergistic effects of widespread coastal urbanization and climate change impacts will likely limit future habitat management effectiveness in the

Patricia Varela

pvarela@geosyntec.com

1 Southern California Coastal Water Research Project, Costa Mesa, CA, USA

2 Tampa Bay Estuary Program, St. Petersburg, FL, USA

3 Gulf Coast Ecosystem Restoration Council, New Orleans, LA, USA

4 Tulane University School of Public Health and Tropical Medicine, New Orleans, LA, USA

5 Montana State University, Bozeman, MT, USA

6 Geosyntec Consultants Inc., Houston, TX, USA 
southeast USA (Enwright et al. 2016). Competing management and policy directives for flood protection, national commerce, and energy development complicate and prolong efforts to abate coastal hypoxia and other coastal water quality issues (Rabotyagov et al. 2014; Alfredo and Russo 2017). Disputes surrounding fair and equitable natural resource allocation often result in contentious implementation plans for the long-term sustainability of coastal resources (GMFMC 2017). Further, discrete tropical storm (Greening et al. 2006) and large-scale pollution events (Beyer et al. 2016) often reset, reverse, or delay progress in restoring coastal ecosystems. These factors contribute to a complex setting for successful implementation of ecosystem restoration activities within the GOM.

In addition to these challenges, the difficulties of rigorously monitoring and understanding an ecosystem's condition and restoration trajectory at various spatial and temporal scales can further constrain evaluations of restoration success (Hobbs and Harris 2001; Liang et al. 2019). The lack of long-term environmental monitoring is a primary impediment to understanding pre- versus post-restoration change (Schiff et al. 2016) and also impedes recognition of any coastal ecosystem improvements derived from prolonged management, policy, and restoration activities. Long-term coastal monitoring programs can facilitate a broader sense of how management, policy, and restoration activities affect coastal ecosystem quality (Borja et al. 2016). Utilizing lessons learned from environmental monitoring programs, new frameworks are starting to emerge to better understand and facilitate coastal restoration ecology (Bayraktarov et al. 2016; Diefenderfer et al. 2016).

A very large, comprehensive, and concerted effort to restore Gulf of Mexico coastal ecosystems is currently underway (GCERC 2013, 2016). Primary funding for this effort is derived from the legal settlements resulting from the 2010 Deepwater Horizon oil spill. Funding sources include early restoration investments that were made immediately following the spill, natural resource damage assessments resulting from the spill's impacts (NRDA 2016), a record legal settlement of civil and criminal penalties negotiated between the responsible parties and the US government with strict US congressional oversight (United States vs. BPXP et al.), and matching funds from research, monitoring, and restoration practitioners worldwide. These funds, equating to $>\$ 20 \mathrm{~B}$ US, present the Gulf of Mexico community an unprecedented opportunity to revitalize regional restoration efforts that will span multiple generations (GCERC 2013, 2016). Consequently, the restoration investments being made with these funds will be highly scrutinized. Better understanding the environmental outcomes of past restoration investments will help identify how, where, and when future resources should be invested so that the Gulf Coast community can achieve the highest degree of restoration success.
Tampa Bay (Florida, USA) is the second largest estuarine embayment in the GOM, and improvement in condition over the last four decades is one of the most exceptional success stories for coastal water quality management (Greening and Janicki 2006; Greening et al. 2014). Most notably, seagrass coverage in 2016 was reported as 16,857 ha baywide, surpassing the goal of restoring coverage to $95 \%$ that occurred in 1950 (Sherwood et al. 2017). Reductions in nutrient loading (Poe et al. 2005; Greening et al. 2014) and chlorophyll-a concentrations (Wang et al. 1999; Beck and Hagy 2015) and improvements in water clarity (Morrison et al. 2006; Beck et al. 2018) have also preceded the seagrass recovery. Most of these positive changes have resulted from management efforts to reduce point source controls on nutrient pollution in the highly developed areas of Hillsborough Bay (Johansson 1991; Johansson and Lewis 1992). These controls allowed nutrient and chlorophyll-a targets to be met by the early 1990s. However, numerous smaller projects, including watershedfocused efforts (Lewis et al. 1998), may have had a supporting role in maintaining water quality improvements through contemporary periods. The cumulative effects of over 900 restoration projects, relative to broad watershedscale management efforts, are not well understood. Understanding how implementation of these projects is associated with adjacent estuarine water quality at various spatiotemporal scales will provide an improved understanding of the link between overall estuary improvements and specific restoration activities.

Demonstrating success for restoration activities is challenging for several reasons (Ruiz-Jaen and Aide 2005; Wortley et al. 2013). Success may be vaguely or even subjectively defined because the effects of restoration could be described in different ways depending on project goals (Zedler 2007). For example, site-specific measures of before/after condition are commonly used measures of success, whereas downstream effects may be more important to consider for baywide conditions (Diefenderfer et al. 2011). More importantly, quantifying success as a measure of environmental improvements is challenged by the variety of factors that affect water quality across space and time. New tools are needed that can address these challenges to help guide and support GOM restoration. Here, we present an empirical framework for evaluating the influence of restoration projects on water quality improvements within Tampa Bay. The framework helps synthesize routine, ambient monitoring data across various spatiotemporal scales to demonstrate how coastal restoration activities cumulatively affect estuarine water quality improvement. Data on water quality and restoration projects in the Tampa Bay area were used to demonstrate application of the analysis framework. Water quality and restoration datasets were evaluated to identify (1) the types of restoration activities that most improve water quality and (2) the time frames over which 
water quality benefits resulting from restoration may be resolved. Changes in chlorophyll-a concentrations, a proxy for negative eutrophication effects within Tampa Bay (Greening et al. 2014), were used as the success metric to evaluate estuarine restoration activities.

\section{Methods}

\section{Study Area}

Tampa Bay is located on the west-central GOM coast of the Florida Peninsula. Its watershed is among the most highly developed regions in Florida (Fig. 1). More than $60 \%$ of land use within $15 \mathrm{~km}$ of the Bay shoreline is urban or suburban (SWFWMD 2018). The Bay has been a focal point of economic activity since the 1950 s and currently supports a mix of industrial, private, and recreational activities. The watershed includes one of the largest phosphate production regions in the country, which is supported by port operations primarily in the northeast portion of the Bay (Greening et al. 2014).
Current water quality in Tampa Bay is dramatically improved from the degraded historical condition. Nitrogen loads into the Bay in the mid-1970s have been estimated as $8.9 \times$ $10^{6} \mathrm{~kg} /$ year, largely from wastewater effluent (Greening et al. 2014). In addition to reduced esthetics, hypereutrophic environmental conditions were common and included elevated chlorophyll-a and harmful algae, and reduced bottom waterdissolved oxygen, water clarity, and seagrass coverage. Yields for some commercial and recreational species were also depressed, although emergent tidal wetland loss and fisheries practices (i.e., widespread Bay trawling and gill-netting) likely also contributed to declines (Comp 1985; Lombardo and Lewis 1985).

A long-term monitoring program in Tampa Bay has been instrumental in assessing and tracking restoration efforts. In the early 1970s, the initial baywide ambient monitoring program was established by a local environmental leader (Roger Stewart), which was subsequently institutionalized through State legislation by the creation of the Environmental Protection Commission of Hillsborough County. This occurred largely in response to citizen outcry of the Bay's
Fig. 1 Water quality stations and restoration projects in the Tampa Bay area. Water quality stations have been monitored monthly since 1974. Locations of restoration projects represent 887 records that are generally categorized as habitat or water infrastructure projects from 1971 to present. Bay segments as management units of interest are shown in the upper right inset. HB, Hillsborough Bay; LTB, Lower Tampa Bay; MTB, Middle Tampa Bay; OTB, Old Tampa Bay. Water quality data from the Hillsborough County

Environmental Protection Commission (TBEP 2017) and restoration project data from the Tampa Bay Water Atlas (http:// maps.wateratlas.usf.edu/ tampabay/; TBEP 2017), US EPA National Estuary Program Mapper (https://gispub2.epa.gov/ NEPmap/), and the Tampa Bay Estuary Program Action Plan Database Portal (https://apdb. tbeptech.org/index.php)

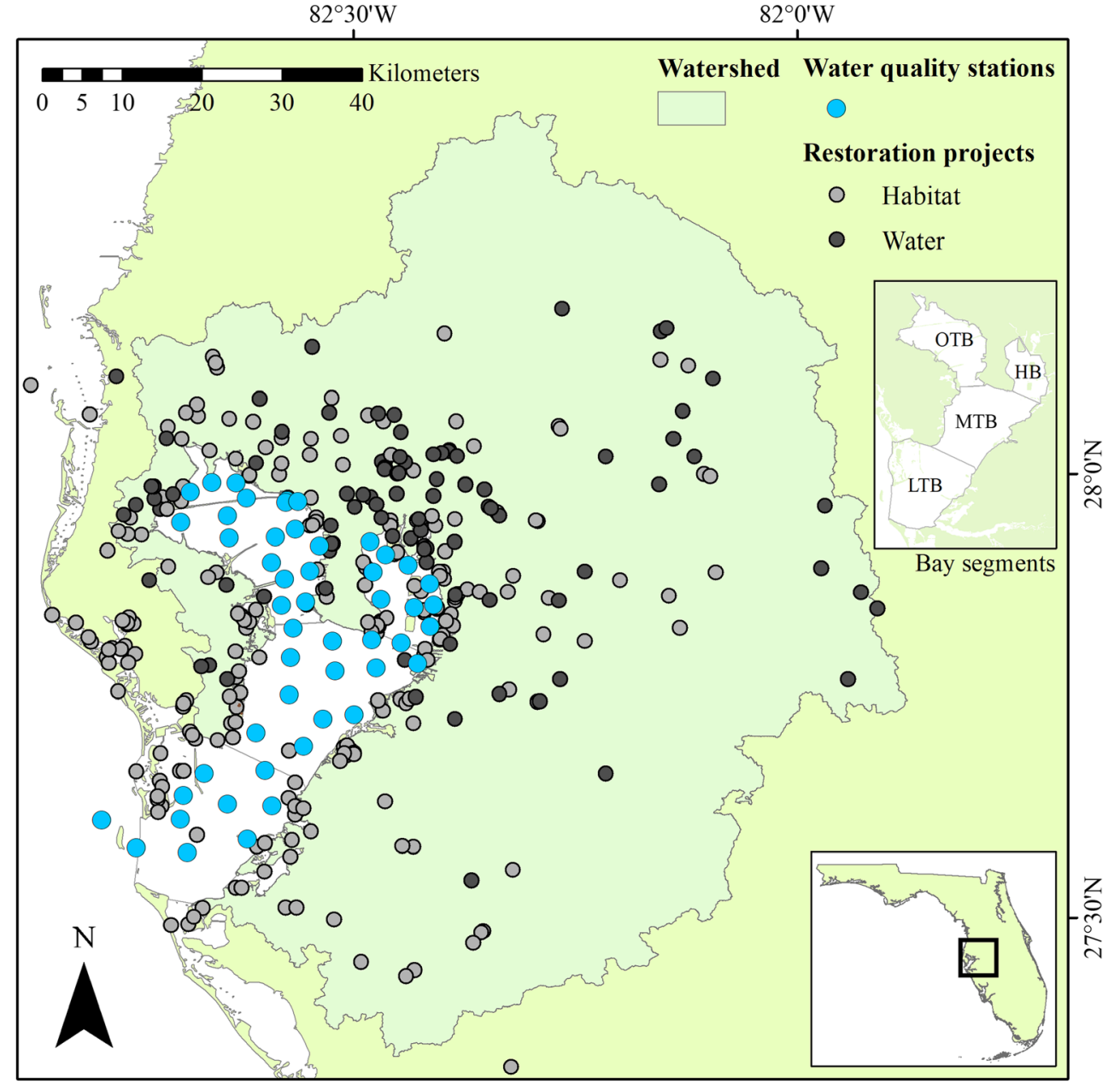


deteriorating ecology (Greening et al. 2014). Ongoing local support for this program has remained since 1972, and other local, municipal governments have created complementary water quality monitoring programs, all of which now support water quality assessments and management efforts spearheaded by the Tampa Bay Estuary Program (Sherwood et al. 2016). Some of the key attributes supporting the maintenance of this long-term monitoring program are summarized in Schiff et al. (2016) and Gross and Hagy (2017).

Nearly 900 public and private projects to improve water quality have also been completed in Tampa Bay and its watershed over the past four decades. These projects represent numerous voluntary (e.g., coastal habitat acquisition, restoration, preservation, etc.) and compliance-driven (e.g., stormwater retrofits, process water treatment upgrades, sitelevel permitting, power plant scrubber upgrades, improved agricultural practices, residential fertilizer use ordinances, etc.) activities. Linking data from the long-term monitoring program with data on these projects will provide an understanding of how the cumulative effects of small-scale restoration have contributed to water quality relative to the historical water infrastructure upgrades.

\section{Data Sources}

Several databases were combined to document restoration projects in Tampa Bay and its watershed. Each database was unique and no overlap in documented projects was observed. Data from the Tampa Bay Water Atlas (version 2.3, http:// maps.wateratlas.usf.edu/tampabay/; TBEP 2017) documented 253 projects from 1971 to 2007 that were primarily focused on habitat establishment, enhancement, or protection along the Bay's immediate shoreline or within the larger watershed area. Examples include restoration of salt marshes and mangroves, exotic vegetation control, and conversion of agricultural lands to natural habitats. Information on an additional 265 recent (2008-2017) projects was acquired from the US EPA's National Estuary Program Mapper (https://gispub2.epa.gov/NEPmap/). This database provides only basic information, such as year of completion, geographic coordinates, general activities, and areal coverage. Data from the TBEP Action Plan Database Portal (https://apdb.tbeptech.org/index.php) documented locations of infrastructure improvement projects, structural best management practices, and policy-driven stormwater or wastewater management actions. This database included 368 projects from 1992 to 2016 for county, municipal, or industrial activities, such as implementation of best management practices at treatment plants, creation of stormwater retention or treatment controls, or site-specific controls of industrial and municipal point sources.

For all restoration datasets, shared information included the project location, year of completion, and classification of the restoration activity. We developed and applied a two-level classification scheme that described each restoration project as (1) a habitat or water infrastructure improvement and (2) more specifically as enhancement, establishment, or protection for habitat or as nonpoint or point source controls for water infrastructure. These categories were used to provide a broad characterization of restoration activities that were considered to contribute to improvements in water quality over time. The final combined dataset included 887 projects from 1971 to 2017 (Fig. 2). Projects with incomplete information were not included in the final dataset.

Water quality data in Tampa Bay have been collected consistently since 1974 by the Environmental Protection Commission of Hillsborough County (Sherwood et al. 2016; TBEP 2017). Data were collected monthly at 45 stations using a water sample or monitoring sonde at bottom, mid-, or surface depths, depending on parameter. The locations of monitoring stations were fixed and cover the entire Bay from the uppermost mesohaline sections to the lowermost euhaline portions that have direct interaction with the GOM (Fig. 1). Middepth water samples at each station are laboratory processed immediately after collection. Chlorophyll-a $(\mu \mathrm{g} / \mathrm{L})$ and total nitrogen $(\mathrm{mg} / \mathrm{L})$ measurements at each site were used for analysis, totaling up to 515 discrete observations for each station. Total nitrogen concentrations were included in initial data assessments, as this nutrient is considered limiting in Tampa Bay (Greening et al. 2014).

\section{Data Synthesis and Analysis Framework}

The five subcategories for each project (habitat enhancement, establishment, and protection; nonpoint and point source controls) were separately evaluated to describe the likelihood of changes in water quality associated with each type. Water quality monitoring sites were matched to the closest selected restoration projects, and changes in the water quality data were evaluated relative to the completion dates of the selected projects. Spatial and temporal matching can be accomplished using several methods that vary in complexity. For example, hydrologic distances or other non-Euclidean distance weightings by watershed topology can be used to link measurements to modeled locations in space (Curriero 2006; Gardner et al. 2011). However, we adopted a relatively simple approach with limited data requirements to maximize potential applications in other regions (e.g., no hydrology data are needed, only spatial location). The matchings began with a spatial joint wherein the Euclidean distances between each water quality station and each restoration project were quantified. The restoration projects closest to each water quality station were identified using the distances between projects and water quality stations. The distances were also grouped by the five restoration project types (i.e., habitat protection, nonpoint source control, etc.) such that the closest $n$ sites of a 
(a) Counts of restoration project types over time

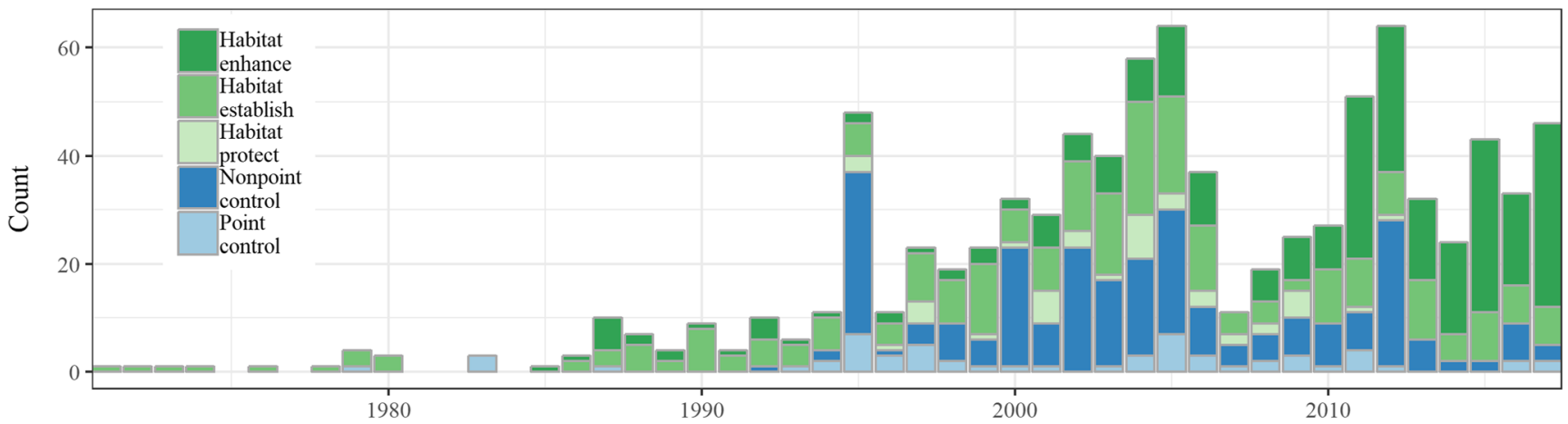

(b) Locations of restoration project types over time
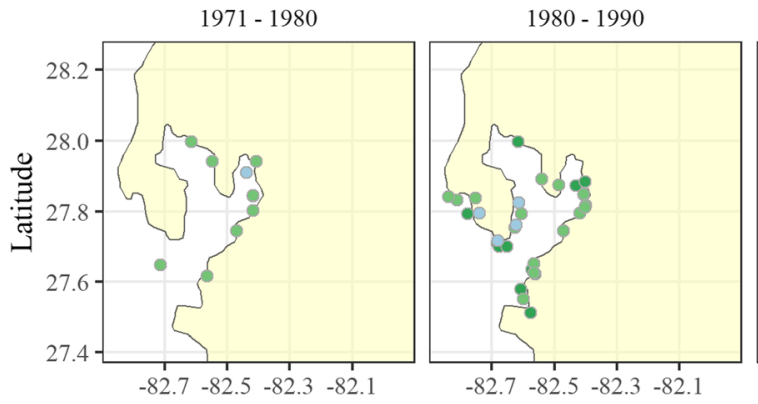

$1990-2000$

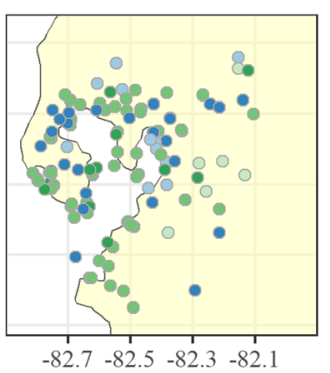

Longitude
$2000-2010$

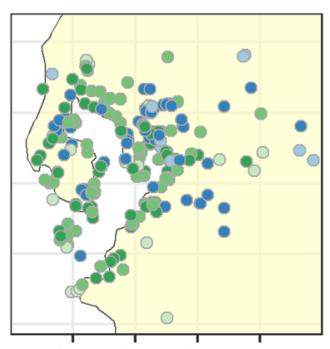

$-82.7-82.5-82.3-82.1$
$2010-2017$

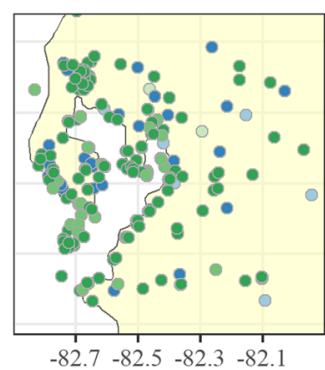

Fig. 2 Counts (a, top) and locations (b, bottom) of restoration project types over time in the Tampa Bay watershed. Restorations were categorized as water infrastructure (blue; nonpoint source controls, point source controls) and habitat (green; enhancements, establishments, protection) projects. The compiled restoration database included records of 887 project types and locations from 1971 to 2017 given project type could be identified for any water quality station (Fig. 3).

For each spatial match, temporal matching between water quality stations and restoration projects was obtained by subsetting the water quality data within a time window before and after the completion date of each restoration project (Fig. 4). For the closest $n$ restoration sites for each of the five project types, two summarized water quality estimates were obtained to quantify a before and after estimate of chlorophyll-a associated with each project. The before estimate was the average of observations for the year preceding the completion of a project and the after estimate was the average of observations for a selected window of time (e.g., 5 years) that occurred after completion of a project. The before estimate for the year prior established the basis of comparison for the water quality estimates in the selected window of time after project completion, where the latter could be manually changed to characterize a potential duration of time within which water quality could improve after project completion. The final two estimates of the before and after values of the five types of restoration projects at each water quality station were based on an average of the $n$ closest restoration sites, weighted inversely by distance from the monitoring station. Lastly, no data were available on project duration and we assumed that the year associated with each project was generally inclusive of project implementation and completion. Time windows that overlapped the start and end date of the water quality time series were discarded.

Change in water quality relative to each type of restoration project was estimated as:

$\Delta \mathrm{WQ}=\frac{\sum_{i=1}^{n} \widehat{\mathrm{wq}} \in \mathrm{win}+\operatorname{proj}_{i, \mathrm{dt}}}{n \times \text { dist }_{i \in n}}-\frac{\sum_{i=1}^{n} \widehat{\mathrm{wq}} \in \operatorname{proj}_{i, \mathrm{dt}}-\mathrm{win}}{n \times \text { dist }_{i \in n}}$

where $\triangle \mathrm{WQ}$ was the difference between the after and before averages for each of $n$ spatially matched restoration projects. For each $i$ of $n$ projects (proj), the average water quality (wq ) within the window (win) either before $\left(\operatorname{proj}_{i, \mathrm{dt}}-\right.$ win) or after $\left(\right.$ win $\left.+\operatorname{proj}_{i, \mathrm{dt}}\right)$ the completion date $(\mathrm{dt})$ for project $i$ was summed. The summations of water quality before and after each project were then divided by the total number of $n$ matched projects, multiplied by the distance of the projects from a water quality station ( dist $\left._{i \in n}\right)$. This created a weighted average of the before-after estimates for each project that was inversely related to the distance from a water quality station. A weighted average by distance (or parametric distance weights; Sickle and Johnson 2008) was used based on the assumption that restoration projects farther from a water quality station will have a weaker association with potential changes in chlorophyll-a. The total change in water quality for a project type 
Water quality stations

Closest match by project type

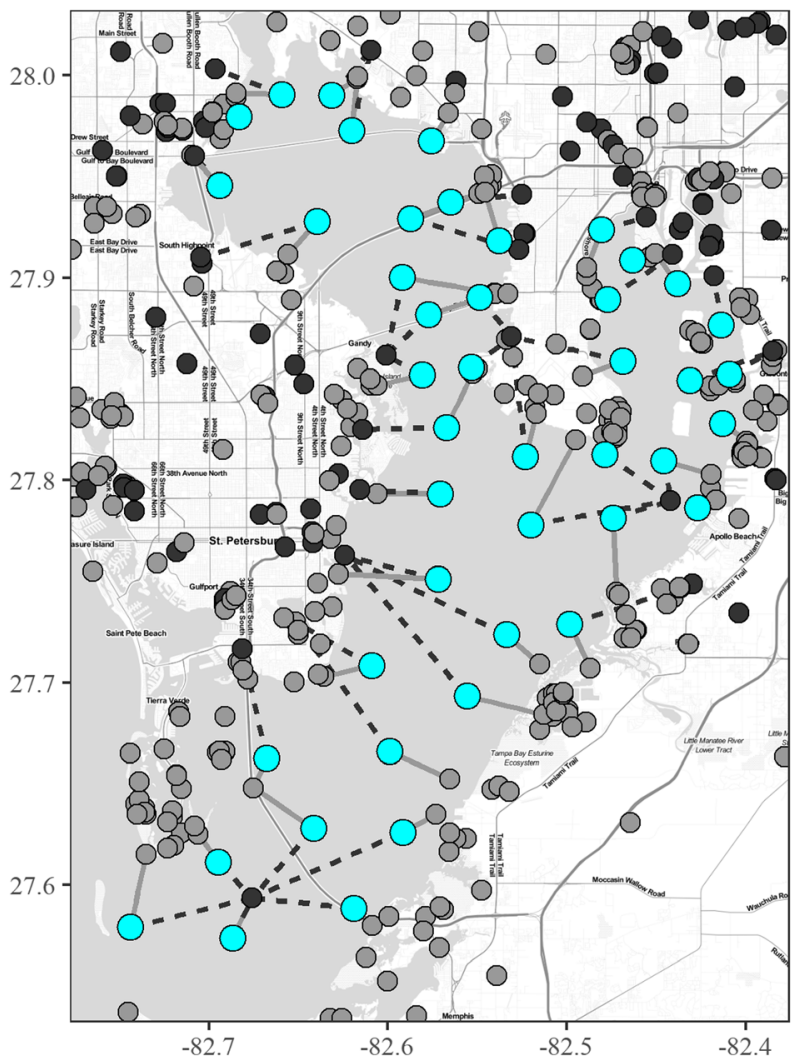

Fig. 3 Spatial matching of water quality stations with restoration projects. Spatial matches of each water quality station (blue dots) with habitat (solid line to gray dots) and water infrastructure (dashed line to black dots) projects are shown as the closest single match by type on the left

was simply the difference in weighted averages. This process was repeated for every station (Fig. 5). Overall differences
Closest "n" matches

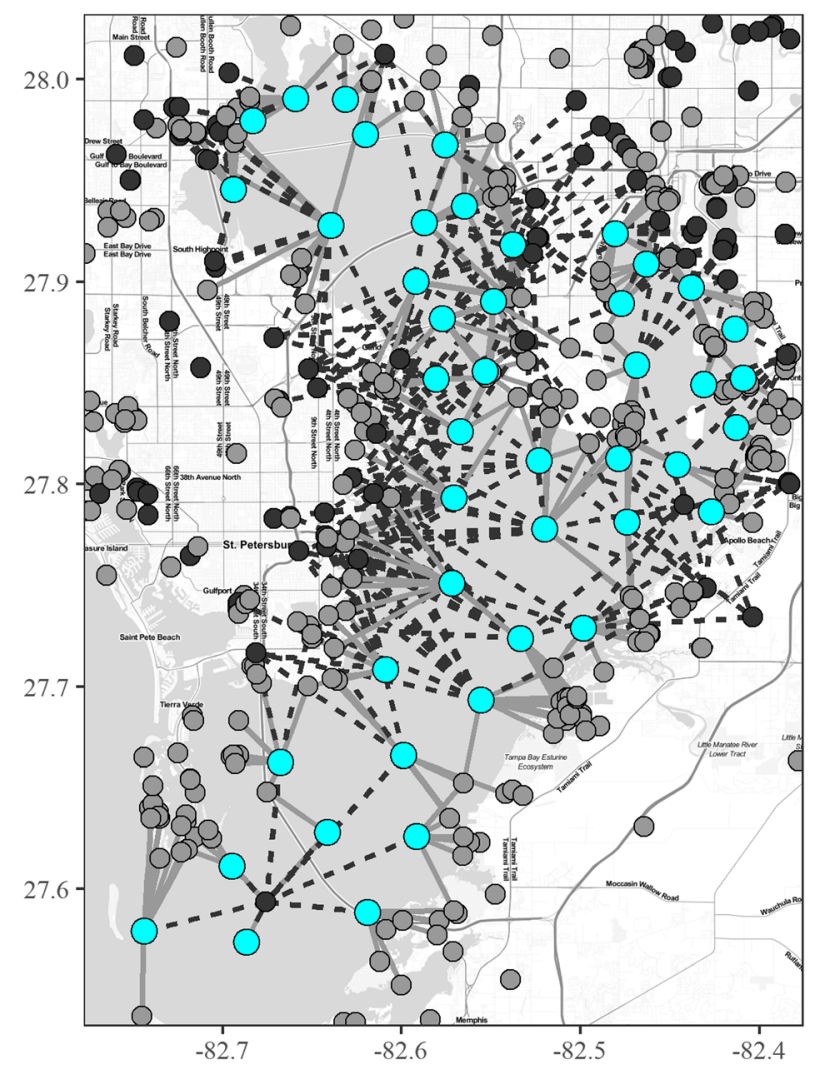

and the " $n$ " closest matches on the right. The spatial matches were made for the five restoration project types within the broader habitat and water categories shown in the figure

between project types were evaluated by ANOVA $F$ tests, whereas pairwise differences between project types were (a) Spatial match

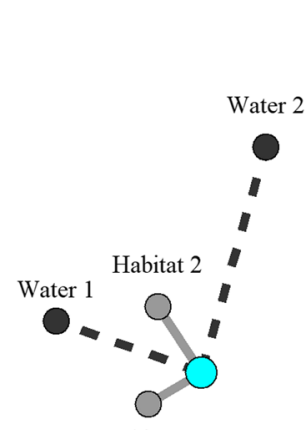

Habitat 1

(b) Temporal match

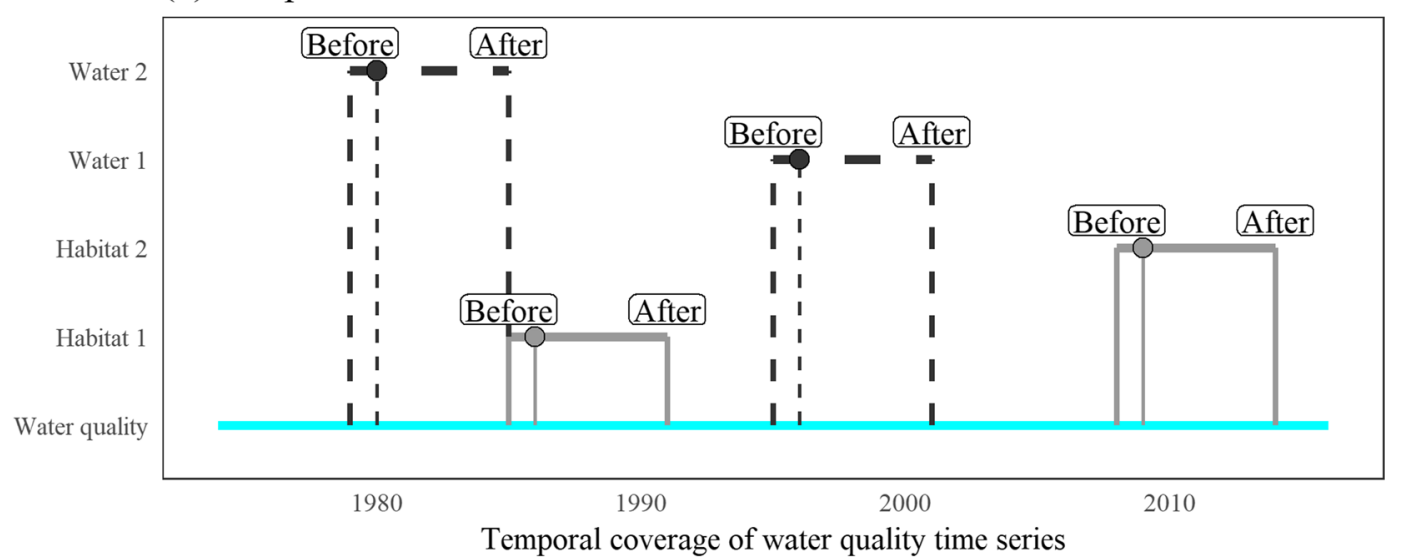

Fig. 4 Temporal matching of restoration project types with time series data at a water quality station. The restoration project locations that are spatially matched with a water quality station (a) are used to create a temporal slice of the water quality data within a window of time before and after the completion date of each restoration project (b). Slices are based on the closest " $n$ " restoration projects by type $(n=2$ in this example) to a water quality station. The two broad categories of habitat and water infrastructure projects are shown in the figure as an example, whereas the analysis evaluated all five restoration categories 
Habitat Habitat $\quad$ Habitat $\quad$ Nonpoint $\quad$ Point

(a) Example station match with restoration projects

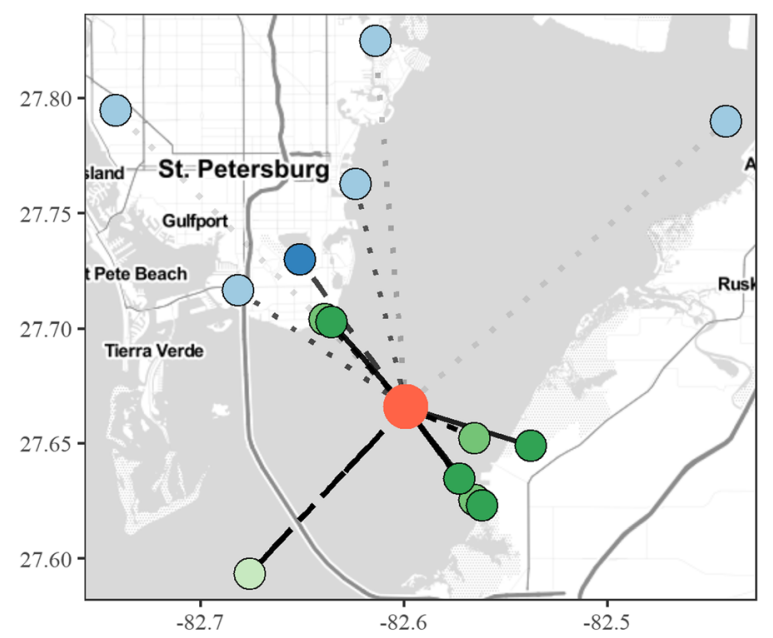

(c) Before/after averages

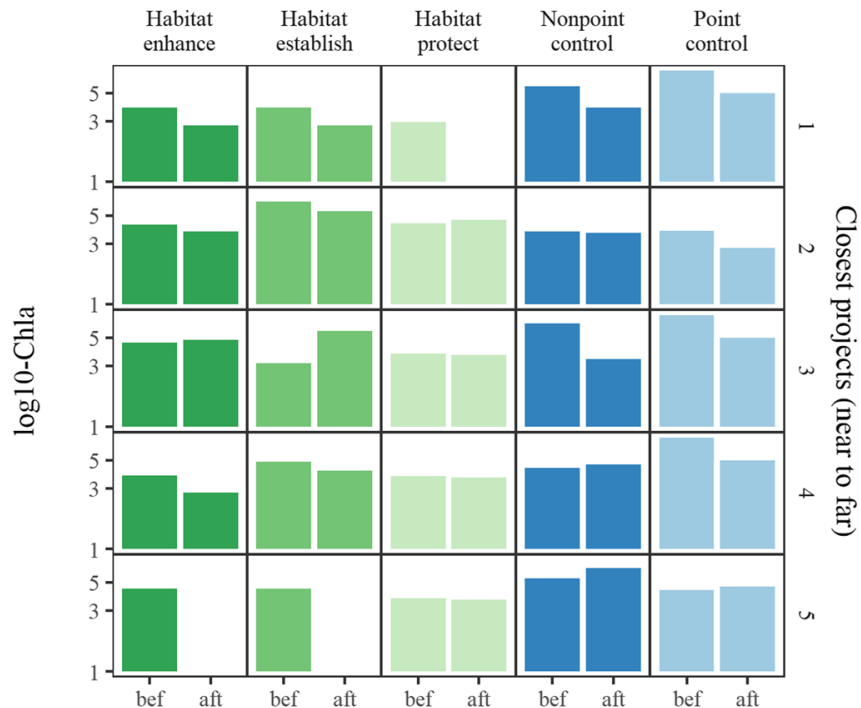

(b) Chlorophyll time slices

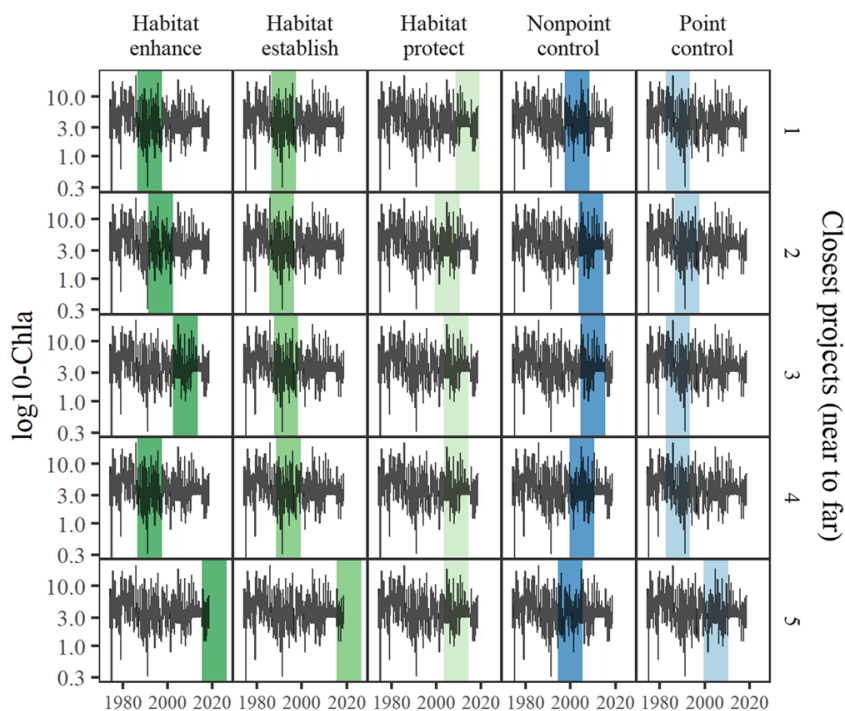

(d) Before/after differences

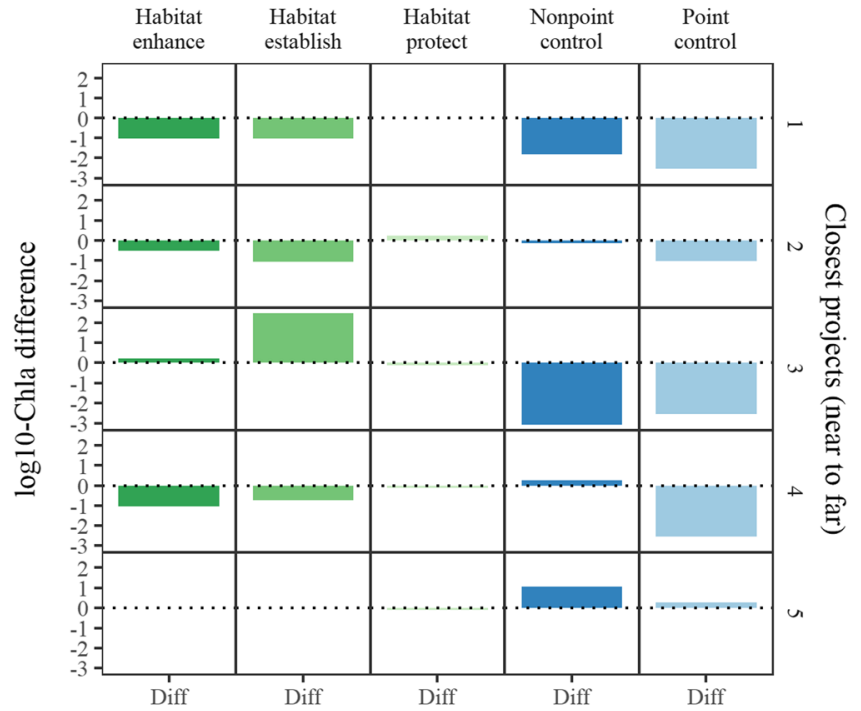

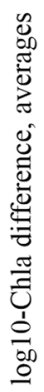

(e) Combined estimated effects, $\Delta W Q$ in eq. (1) for each of five project types

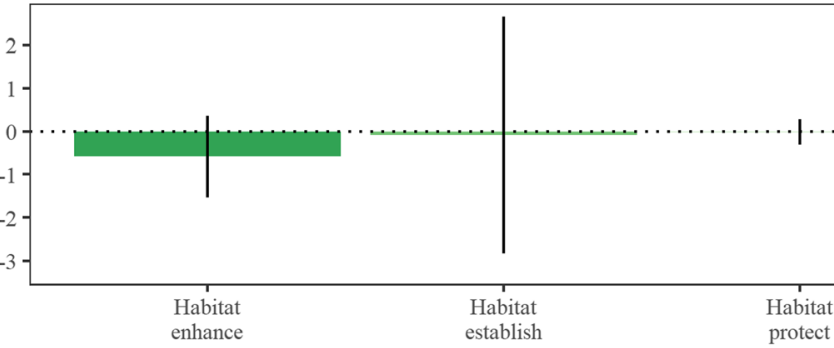

Fig. 5 Steps to estimate cumulative water quality changes at a single station associated with a selected number of projects and time windows. Subplot (a) shows a station in Middle Tampa Bay matched to the five nearest restoration projects for each of five types (some are co-located). The time slices of the water quality observations for 1 year prior and
10 years after the completion of each project are shown in (b), ordered from near to far. The before/after water quality averages for the slices are shown in (c) and the differences between the two are shown in (d). Finally, the weighted averages for the five closest matches by project type are shown in (e) with $95 \%$ confidence intervals 
evaluated by $t$ tests with corrected probability values for multiple comparisons.

One of the key assumptions of our approach is that restoration projects will benefit water quality through a reduction in chlorophyll-a. We make no assumptions about the expected magnitude of an association given that the model does not describe a specific mechanism of change, nor do we make any explicit assumption about the direction of change (i.e., two-tailed hypothesis tests were used), although a general assumption was that chlorophyll-a would decrease over time in agreement with known changes in water quality. However, we hypothesized that the magnitude of chlorophyll-a changes varies by project type and number of projects or length of time window evaluated. An expected outcome is that explicit, quantitative conclusions can be made about the relative differences between projects types, particularly regarding how additional projects of a particular type could benefit water quality and within what general time windows a change might be expected (Diefenderfer et al. 2011).

The model was also designed to quantify cumulative relationships of restoration projects with water quality at different spatial scales. In Eq. (1), the association of a restoration type with chlorophyll-a is estimated for one water quality station, whereas estimates from several water quality stations can be combined to develop an overall description of a particular restoration type as it applies to an areal unit of interest, potentially over broad regional scales. For example, estimated associations of point source control projects with each water quality station in the Bay can be combined to develop an overall narrative of how these projects could (assuming a causal relationship) influence environmental change across the entire Bay. Estimates across stations were evaluated to describe associations in baywide improvements from various restoration project types throughout the watershed. Estimates were also evaluated by individual Bay segments that have specific management targets for chlorophyll-a concentration (Florida Statute 62-302.532; Janicki et al. 1999). Stratification by Bay segments provided an alternative context for interpreting the results based on areal differences between segments and how restoration projects varied in space and time. Evaluating the results at different scales can also provide insights into potential (or lack of) stressors and processes controlling the impacts, which can help prioritize management actions by location (Diefenderfer et al. 2009; Thom et al. 2011).

The analysis of each project type was bounded by two key parameters in Eq. (1). These include $n$, the number of spatially matched restoration projects used to average the cumulative estimate of each project type, and win, the time windows before and after a project completion date that were used to subset a station's water quality time series. These boundaries affected our ability to characterize each restoration project type with water quality changes. Identifying values that maximized the difference between before and after water quality measurements was necessary to quantify how many projects were most strongly associated with a change in water quality, the time within which a change is expected, and the magnitude of an expected change between project types. For simplicity, we evaluated different combinations of 5- or 10-year time windows from the date of each project completion and the 5 or 10 closest projects to each water quality station. All analyses were conducted with customized scripts created for the $\mathrm{R}$ statistical programming language (RDCT 2018).

\section{Testing Effects of Restoration Dates and Location}

Because of the documented improvements in water quality in Tampa Bay, a concern with our approach is that any association between restoration projects and chlorophyll-a may result from correlations between the two parameters, confounding a true demonstration of water quality improvements in relation to restoration activities. To address this challenge, estimated changes in chlorophyll-a were evaluated in response to temporal and spatial matching with restoration projects, as above, but with random date and location assignments for each restoration project that were then compared to the actual results. An expected outcome of randomization is that no differences are observed between project types and that all associations between projects and chlorophyll-a changes should reflect the continuous decline of chlorophyll-a over time, as observed in the independent water quality record. In other words, the randomization creates a null model where the estimated effects of restoration projects would not differ from a simple evaluation of trends in the raw data - slicing the observed time series by random dates and evaluating before/after averages with random projects is expected to reflect the known decline of chlorophyll-a in the raw data. Alternatively, evidence that our framework provides meaningful results would be supported by differences in chlorophyll-a changes between project types and the timing associated with the changes.

\section{Results}

\section{Water Quality Observations}

Chlorophyll-a in Tampa Bay decreased over the 40-year record consistent with documented changes (Wang et al. 1999; Greening et al. 2014; Beck and Hagy 2015) (Table 1). Median concentrations were highest from 1977 to 1987 (median $13.40 \mu \mathrm{g} / \mathrm{L}$ at low salinity stations $<26.5 \mathrm{psu}, 7.30 \mu \mathrm{g} / \mathrm{L}$ at high salinity stations $>26.5 \mathrm{psu}$ ). Declines were monotonic throughout the period of record with the largest reductions occurring during the first 20 years ( $34 \%$ decrease), followed by consistent but smaller reductions in concentrations later in the time series. A $34 \%$ decrease at low salinity stations and a $30 \%$ decrease at high salinity stations were observed between the 
Table 1 Summary of total nitrogen and chlorophyll-a observations from monitoring stations in Tampa Bay

\begin{tabular}{|c|c|c|c|c|c|c|c|}
\hline \multirow[t]{2}{*}{ Salinity } & \multirow[t]{2}{*}{ Time period } & \multicolumn{3}{|c|}{ Total nitrogen $(\mathrm{mg} / \mathrm{L})$} & \multicolumn{3}{|c|}{ Chlorophyll-a $(\mu \mathrm{g} / \mathrm{L})$} \\
\hline & & Min & Median & Max & Min & Median & Max \\
\hline \multirow[t]{8}{*}{ Low } & JFM & 0.00 & 0.46 & 2.69 & 0.12 & 5.30 & 114.4 \\
\hline & AMJ & 0.03 & 0.59 & 3.03 & 0.20 & 8.40 & 183.40 \\
\hline & JAS & 0.02 & 0.64 & 3.02 & 0.50 & 13.80 & 266.60 \\
\hline & OND & 0.03 & 0.57 & 4.14 & 0.00 & 10.00 & 192.14 \\
\hline & $1977-1987$ & 0.02 & 0.88 & 3.03 & 0.10 & 13.40 & 266.60 \\
\hline & 1987-1997 & 0.05 & 0.73 & 4.14 & 0.00 & 8.78 & 192.14 \\
\hline & $1997-2007$ & 0.00 & 0.54 & 2.89 & 0.12 & 7.86 & 261.90 \\
\hline & $2007-2017$ & 0.03 & 0.42 & 2.75 & 0.50 & 7.40 & 220.60 \\
\hline \multirow[t]{8}{*}{ High } & JFM & 0.03 & 0.43 & 1.65 & 0.00 & 3.20 & 55.80 \\
\hline & AMJ & 0.02 & 0.48 & 1.95 & 0.10 & 5.40 & 74.90 \\
\hline & JAS & 0.03 & 0.54 & 3.16 & 0.10 & 7.23 & 333.40 \\
\hline & OND & 0.02 & 0.43 & 2.43 & 0.00 & 4.67 & 142.90 \\
\hline & $1977-1987$ & 0.02 & 0.57 & 1.92 & 0.30 & 7.30 & 136.80 \\
\hline & 1987-1997 & 0.02 & 0.54 & 2.43 & 0.00 & 5.11 & 142.90 \\
\hline & 1997-2007 & 0.02 & 0.56 & 3.16 & 0.00 & 4.80 & 72.30 \\
\hline & $2007-2017$ & 0.03 & 0.33 & 1.80 & 0.80 & 3.70 & 333.40 \\
\hline
\end{tabular}

Minimum, median, and maximum observed values for low and high salinity conditions are shown for seasonal and annual aggregations of water quality observations at all monitoring stations (see Fig. 1). Low or high salinity is based on values below or above the long-term baywide median (26.5 psu)

$J F M$, January, February, March; AMJ, April, May, June; JAS, July, August, September; $O N D$, October, November, December

periods of 1977-1987 and 1987-1997. Seasonally, chlorophyll-a concentrations were highest in the late summer/ early fall periods (median $13.80 \mu \mathrm{g} / \mathrm{L}$ at low salinity stations, $7.23 \mu \mathrm{g} / \mathrm{L}$ at high salinity stations, across all years). Total nitrogen concentrations had similar trends as chlorophyll-a, although a steady decline was observed across the entire time series rather than primarily in the first two decades in contrast to chlorophyll-a (Poe et al. 2005; Greening et al. 2014). An exception for total nitrogen was observed at high salinity stations where concentrations were relatively constant at approximately $0.55 \mathrm{mg} / \mathrm{L}$ from 1987 to 2007. Seasonally, total nitrogen concentrations peaked in the late summer/early fall period.

The monotonic decline in chlorophyll-a concentrations was mirrored by increases in the number and types of restoration projects in the watershed, where the number of documented projects increased after 2000 (Fig. 2). For the entire record, 275 (31\% of total) habitat enhancement, 259 (29\%) habitat establishment, $45(5 \%)$ habitat protection, 248 (28\%) nonpoint source, and $60(7 \%)$ point source control projects were documented. Individual point source controls early in the record were those that occurred in the historically polluted upper Hillsborough Bay and adjacent to the city of St. Petersburg (Johansson 1991; Johansson and Lewis 1992; Lewis et al.
1998). Prior to 1995 , only 11 water infrastructure projects (three nonpoint control, eight point source controls) were documented in the database, whereas 70 habitat projects were recorded (50 habitat establishment, 20 habitat enhancement). Nearly 10 times as many restoration projects were completed in 1995 to present (806 total), with notable increases in the number of nonpoint source controls (245) and habitat protection projects (45).

\section{Associations Between Restoration Projects and Water Quality Change}

Before employing our analytical approach, we evaluated temporal trends in water quality and possible drivers of water quality change to develop an analytical baseline for comparison. A simple analysis of water quality measurements versus the cumulative number of restoration projects over time showed a decrease in both total nitrogen and chlorophyll-a with additional restoration effort. Analysis of median water quality estimates across all monitoring stations for a given year versus the cumulative number of restoration projects as of that year showed that water quality was related to the number of projects for all project types (based on linear models, $\alpha=0.05$; Fig. 6). Associations with the number of projects were relatively strong for total nitrogen and relatively weaker for chlorophyll-a across project types. Decreases in total nitrogen were most strongly associated with water infrastructure projects for nonpoint source $(F=65.5, d f=1,23, p<0.005)$ and point source controls $(F=60.8, d f=1,21, p<0.005)$, as expected. Habitat protection projects were also strongly associated with decreases in total nitrogen $(F=34.8, d f=1,14$, $p<0.005)$. For chlorophyll-a, the strongest associations were observed with habitat establishment $(F=20.8, d f=1,35$, $p<0.005)$ and point source control $(F=13.7, d f=1,22$, $p<0.005)$ projects. A marginally significant association was observed between chlorophyll-a and cumulative habitat protection projects $(F=4.6, d f=1,14, p=0.049)$.

In contrast to the results in Fig. 6, baywide estimates of the effects of restoration projects using spatial-temporal matching depended on the year window sizes and number of nearby restoration projects matched to each water quality station (Fig. 7). Estimated associations of different projects types with chlorophyll-a at individual stations are shown in the left maps and the baywide aggregate associations across all stations for a given project type in the right plots. Station points in the left maps correspond to the change estimate for the year window and closest project type selections for each project type that were obtained through the steps in Fig. 5 and Eq. (1). Stations outlined in black have significant results based on $t$ tests of the mean estimates of chlorophyll-a relative to zero change. The plots on the right are based on the baywide distributions of the estimated water quality changes for all stations for the corresponding project types in the maps on the left. The plots on the 
Year $\bigcirc 1980 \bigcirc 1990 \bigcirc 2000 \bigcirc 2010$
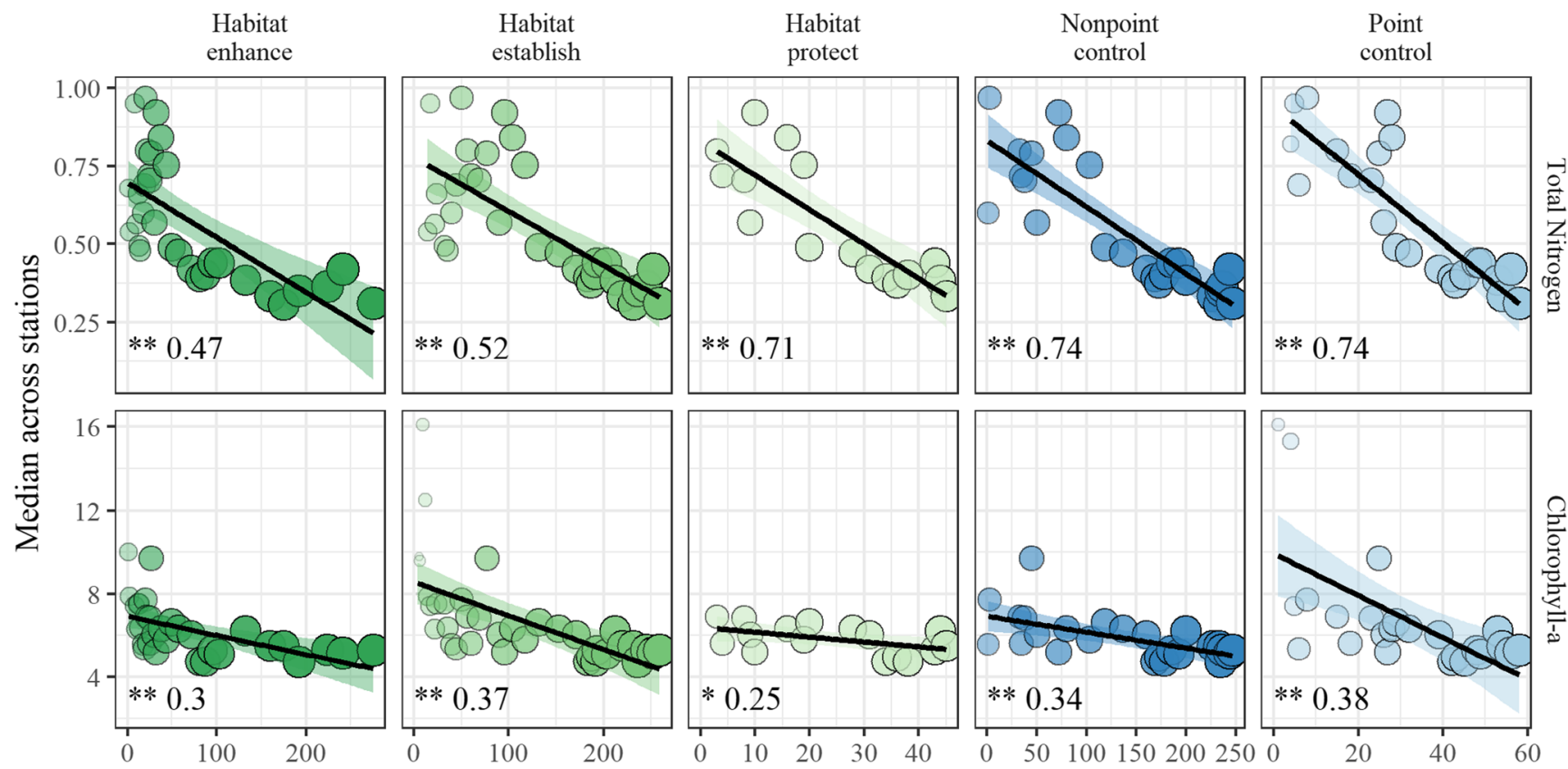

Cumulative number of projects

Fig. 6 Relationships between cumulative number of restoration projects over time and water quality observations in Tampa Bay. The plot shows median total nitrogen $(\mathrm{mg} / \mathrm{L})$ and chlorophyll-a $(\mu \mathrm{g} / \mathrm{L})$ across all monitoring stations for each year against the cumulative number of projects for all preceding years. Points are sized and shaded by year to show the

right also include statistical summaries for (1) an analysis of variance (ANOVA) $F$ test to compare the distribution of water quality changes between project types, (2) individual $t$ tests for each project type to evaluate changes that were different from zero, and (3) a multiple comparison test denoted by letters to identify which project types had changes that were different from each other.

For site-specific estimates of water quality changes, longer time windows and more project matches with each monitoring station increased observations of significant associations (i.e., more black circles in the maps in Fig. 7d, compared to Fig. 7a). This was particularly true for habitat protection projects where no significant associations were observed for the 5-year window, 5 closest projects combination, but 12 stations had significant associations for the 10 -year window, 10 closest projects combination. A similar trend was observed for point source control projects where more stations had more significant reductions in chlorophyll-a with the 10-year window, 10 closest projects. For nonpoint source projects, the greatest number of stations $(n=13)$ with significant improvements in water quality was observed for the 5-year window, 10 closest projects combination. Associations of habitat enhancement and habitat establishment projects with water quality stations were inconsistent, with some sites showing an increase or progression of water quality and number of projects over time. Summary statistics are shown in the bottom left corner as the significance of the linear regression (stars) and $R$-squared value. $p>0.05 \mathrm{~ns},{ }^{*} p<0.05$, $* * p<0.005$

decrease that varied by the year window, closest project combinations. Spatial patterns among stations regarding associations with different project types were also not clear, although point source controls were more commonly associated with improvements in mid-Bay stations (Middle Tampa Bay segment, see Fig. 1).

The estimated baywide effects for each project type showed that point source controls were more strongly associated with reductions in chlorophyll-a than the other project types (Fig. 7, right plots). This association was particularly strong for the 10-year window combinations (Fig. 7c, d), where the results suggested an overall baywide reduction in chlorophyll-a of approximately $2 \mu \mathrm{g} / \mathrm{L}$, depending on the number of projects implemented (median change across all sites: reduction of $2.7 \mu \mathrm{g} / \mathrm{L}$ for 10 years, 5 closest projects and $1.6 \mu \mathrm{g} / \mathrm{L}$ for 10 years, 10 closest projects). Nonpoint source controls were also significantly associated with chlorophyll-a reductions, but only when a large number of projects were implemented (10 closest project combinations, Fig. 7b, d). Additionally, the magnitude of nonpoint source control reductions was less than point source controls (reduction of $0.7 \mu \mathrm{g} / \mathrm{L}$ for 5 years, 10 closest projects and $0.5 \mu \mathrm{g} / \mathrm{L}$ for 10 years, 10 closest projects). Habitat protection projects were also significantly associated with baywide changes for 


$$
\begin{array}{llllll}
\text { Chlorophyll change (ug/L), by site } & -5 & 0 & 5 & 10
\end{array}
$$

(a) 5 year window, 5 closest projects
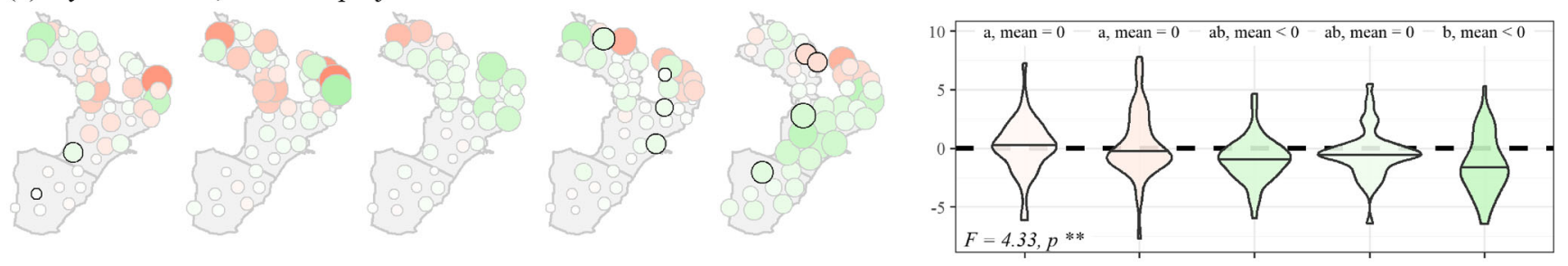

(b) 5 year window, 10 closest projects
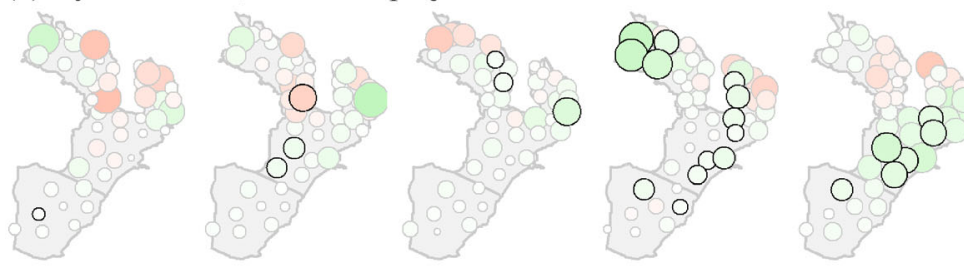

(c) 10 year window, 5 closest projects
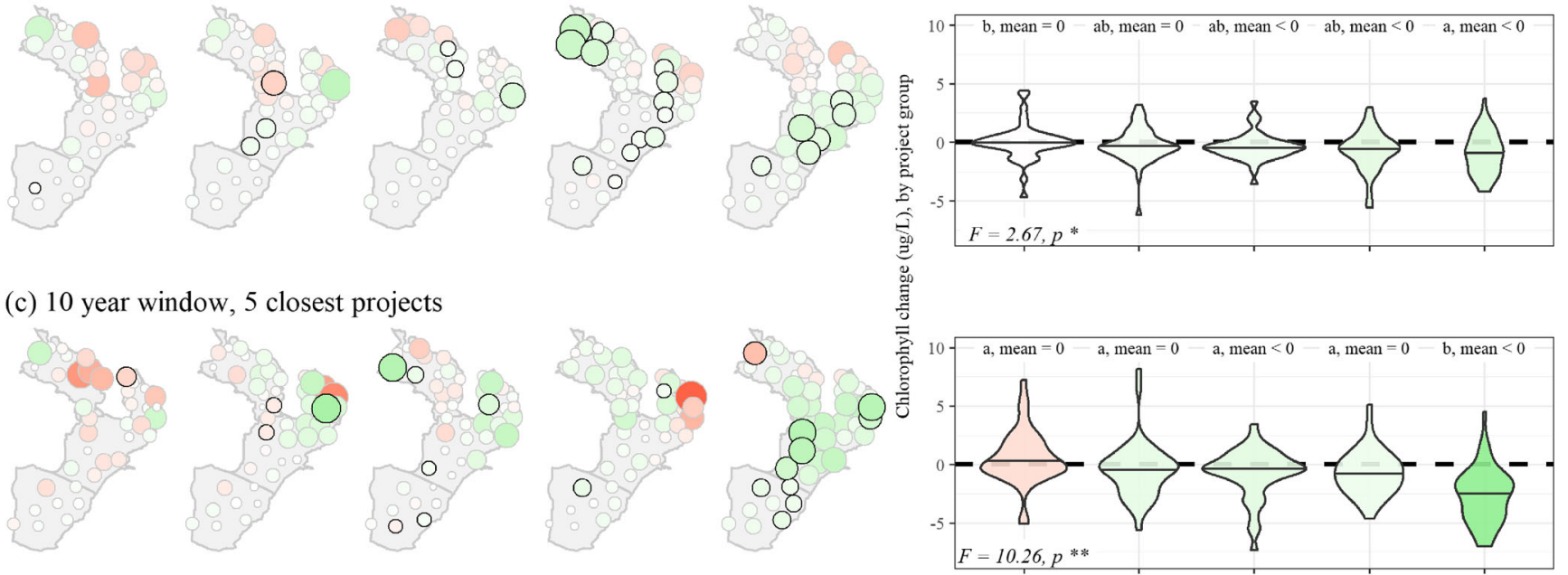

(d) 10 year window, 10 closest projects
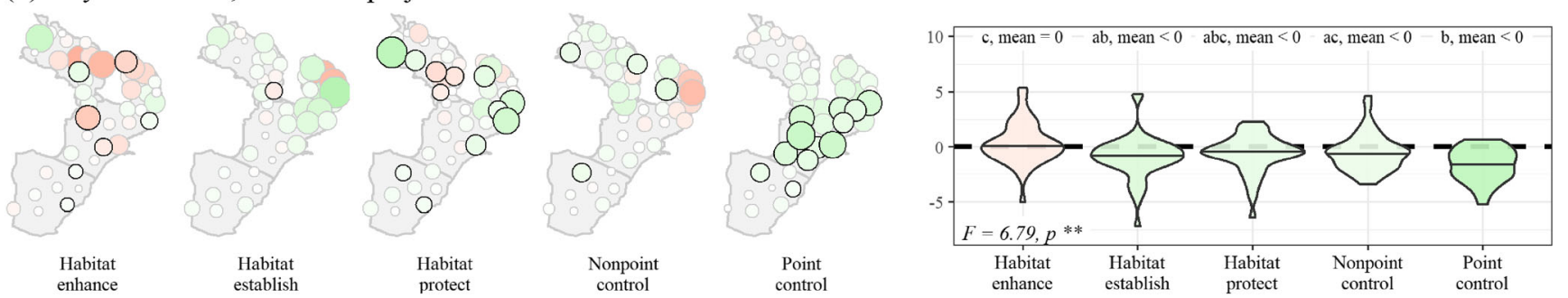

Fig. 7 Associations of restoration projects with chlorophyll-a changes at all sites in Tampa Bay. Associations were evaluated based on different year windows $(5,10)$ since completion of restoration projects and number of closest restoration projects $(5,10)$ to each monitoring station (subfigures a-d). The left plots show the estimated changes at each site (green decreasing, red increasing) for each restoration project type, with significant changes at a site outlined in black. The right plots show the

all year window, closest project combinations, with the largest estimated reduction of $1 \mu \mathrm{g} / \mathrm{L}$ for the 5 -year window, 5 closest projects combination. Habitat enhancement and establishment projects were not strongly associated with baywide changes in chlorophyll-a, with the exception of habitat establishment for the 10 -year window, 10 closest projects combination $(0.9 \mu \mathrm{g} / \mathrm{L}$ reduction $)$.

The above analysis was repeated for individual Bay segments to identify spatial variation in associations of restoration projects with water quality changes. Table 2 provides similar information as the plots on the right side of Fig. 7, where
Within-group average (ug/L), aggregated sites $\begin{array}{lllll} & -2 & -1 & 0\end{array}$ 
Table 2 Associations of restoration projects with chlorophyll-a changes for different segments of Tampa Bay (Fig. 1)

\begin{tabular}{|c|c|c|c|c|c|c|c|}
\hline \multirow[t]{2}{*}{ Combination } & \multirow{2}{*}{$\begin{array}{l}\text { Bay } \\
\text { segment }\end{array}$} & \multirow[t]{2}{*}{ ANOVA } & \multicolumn{5}{|c|}{ Restoration project } \\
\hline & & & $\begin{array}{l}\text { Habitat } \\
\text { enhance }\end{array}$ & $\begin{array}{l}\text { Habitat } \\
\text { establish }\end{array}$ & $\begin{array}{l}\text { Habitat } \\
\text { protect }\end{array}$ & $\begin{array}{l}\text { Nonpoint } \\
\text { control }\end{array}$ & $\begin{array}{l}\text { Point } \\
\text { control }\end{array}$ \\
\hline \multirow[t]{4}{*}{$\begin{array}{l}5 \text { years, } 5 \\
\text { projects }\end{array}$} & $\mathrm{HB}$ & $\begin{array}{c}F=1.09 \\
\text { ns }\end{array}$ & $\mathrm{a}, 0$ & $\mathrm{a}, 0$ & $\mathrm{a},<0$ & $\mathrm{a}, 0$ & $\mathrm{a}, 0$ \\
\hline & LTB & $\begin{array}{c}F=17.37, \\
* *\end{array}$ & $\mathrm{a}, 0$ & $\mathrm{a}, 0$ & $\mathrm{a}, 0$ & $\mathrm{a}, 0$ & $\mathrm{~b},<0$ \\
\hline & MTB & $\begin{array}{c}F=13.5 \\
* *\end{array}$ & $\mathrm{~b}, 0$ & $\mathrm{ab}, 0$ & $\mathrm{a},<0$ & $\mathrm{ab},<0$ & $\mathrm{c},<0$ \\
\hline & OTB & $F=1.5, \mathrm{~ns}$ & $\mathrm{a}, 0$ & $\mathrm{a}, 0$ & $\mathrm{a}, 0$ & $\mathrm{a}, 0$ & $\mathrm{a}, 0$ \\
\hline \multirow[t]{4}{*}{$\begin{array}{c}5 \text { years, } 10 \\
\text { projects }\end{array}$} & HB & $\begin{array}{c}F=0.66 \\
\mathrm{~ns}\end{array}$ & $\mathrm{a}, 0$ & $\mathrm{a}, 0$ & $\mathrm{a}, 0$ & $\mathrm{a}, 0$ & $\mathrm{a}, 0$ \\
\hline & LTB & $\begin{array}{c}F=2.64 \\
\text { ns }\end{array}$ & $a b,<0$ & $a b,<0$ & $\mathrm{ab},<0$ & $\mathrm{a}, 0$ & $\mathrm{~b},<0$ \\
\hline & MTB & $\begin{array}{c}F=18.75 \\
* *\end{array}$ & $\mathrm{a}, 0$ & $\mathrm{a}, 0$ & $\mathrm{a},<0$ & $\mathrm{a},<0$ & $\mathrm{~b},<0$ \\
\hline & OTB & $F=3.11, *$ & $\mathrm{ab}, 0$ & $\mathrm{a}, 0$ & $\mathrm{ab}, 0$ & $\mathrm{~b},<0$ & $\mathrm{a}, 0$ \\
\hline \multirow{4}{*}{$\begin{array}{c}10 \text { years, } 5 \\
\text { projects }\end{array}$} & HB & $F=2.9, *$ & $\mathrm{ab}, 0$ & $a b, 0$ & $\mathrm{ab},<0$ & $\mathrm{a}, 0$ & $\mathrm{~b},<0$ \\
\hline & LTB & $\begin{array}{c}F=6.13 \\
* *\end{array}$ & $\mathrm{a}, 0$ & a, 0 & $\mathrm{a}, 0$ & $a b, 0$ & $\mathrm{~b},<0$ \\
\hline & MTB & $\begin{array}{c}F=14.11, \\
* *\end{array}$ & $\mathrm{a}, 0$ & $\mathrm{a}, 0$ & $\mathrm{a}, 0$ & $\mathrm{a}, 0$ & $\mathrm{~b},<0$ \\
\hline & OTB & $F=3.15, *$ & $\mathrm{~b}, 0$ & $\mathrm{ab}, 0$ & $a b, 0$ & $\mathrm{a},<0$ & $\mathrm{a},<0$ \\
\hline \multirow[t]{4}{*}{$\begin{array}{c}10 \text { years, } 10 \\
\text { projects }\end{array}$} & HB & $\begin{array}{c}F=2.42 \\
\mathrm{~ns}\end{array}$ & $\mathrm{a}, 0$ & a, 0 & $\mathrm{a}, 0$ & $\mathrm{a}, 0$ & $\mathrm{a},<0$ \\
\hline & LTB & $\begin{array}{c}F=1.78 \\
\mathrm{~ns}\end{array}$ & $\mathrm{a}, 0$ & $\mathrm{a},<0$ & $\mathrm{a},<0$ & $\mathrm{a}, 0$ & $\mathrm{a},<0$ \\
\hline & MTB & $\begin{array}{c}F=11.79, \\
* *\end{array}$ & $\mathrm{a}, 0$ & $\mathrm{a},<0$ & $\mathrm{a}, 0$ & $\mathrm{a}, 0$ & $\mathrm{~b},<0$ \\
\hline & ОТВ & $\begin{array}{c}F=2.35 \\
\text { ns }\end{array}$ & $\mathrm{b}, 0$ & $\mathrm{ab},<0$ & $\mathrm{ab}, 0$ & $\mathrm{a},<0$ & $a b,<0$ \\
\hline
\end{tabular}

Associations were evaluated based on different year windows $(5,10)$ since completion of restoration projects and number of closest restoration projects $(5,10)$ to each monitoring station within each segment. Overall differences in chlorophyll-a changes between restoration project types by segment and year/project number combinations were evaluated by ANOVA $F$ tests, whereas pairwise differences (shown as letters) between project types were evaluated by $t$ tests with corrected $p$ values for multiple comparisons. Chlorophyll-a changes by project types that are not significantly different share a letter (comparisons are only valid within rows) and significance of the within-group mean relative to zero is also shown

$H B$, Hillsborough Bay; LTB, Lower Tampa Bay; MTB, Middle Tampa Bay; OTB, Old Tampa Bay $p>0.05 \mathrm{~ns},{ }^{*} p<0.05,{ }^{*} p<0.005$ project combinations, with no clear patterns. Habitat establishment projects were most strongly associated with changes in each Bay segment for the 10-year window, 10 closest projects combination, with the exception of Hillsborough Bay where the relationship was not significant. Chlorophyll-a changes in Lower Tampa Bay were significantly associated with habitat enhancement and establishment projects for the 5-year window, 10 closest projects combination.

\section{Effects of Random Restoration Dates and Locations}

A comparison of the baywide results (Fig. 7, right side) to results from simulations where dates and locations were randomized for each restoration project suggested that the framework in Eq. (1) is robust. The same year windows and closest project combinations were evaluated as above (i.e., 5/10-year windows, $5 / 10$ closest projects), but with 1000 simulations where the date and location of each restoration were randomized (i.e., random draw from uniform distribution of years from 1971 to 2017, random draw from uniform distribution of latitude and longitude based on the bounding box of the study area). Nearly all of the simulated results suggested that each project was associated with a decline in chlorophyll-a (Table 3, values in italics, mean $<0$ ). This is consistent with our null hypothesis that randomization would simply reflect the long-term decline in chlorophyll-a that is apparent in the observed water quality records. Some differences were observed in the 5 years, 5 projects combination where no change $($ mean $=0)$ was the most observed outcome from the simulations. These inconsistencies with our null hypothesis may be 
Table 3 Results comparing water quality associations for random date and location assignments of restoration projects to those from real data

\begin{tabular}{|c|c|c|c|c|c|c|}
\hline Combination & Restoration project & Mean $<0$ & Mean $=0$ & Mean $>0$ & Actual & Agreement \\
\hline \multirow[t]{5}{*}{5 years, 5 projects } & Habitat enhance & 0.44 & 0.51 & 0.06 & Mean $=0$ & $\mathrm{y}$ \\
\hline & Habitat establish & 0.47 & 0.49 & 0.04 & Mean $=0$ & $\mathrm{y}$ \\
\hline & Habitat protect & 0.49 & 0.38 & 0.14 & Mean $<0$ & $\mathrm{y}$ \\
\hline & Nonpoint control & 0.45 & 0.5 & 0.05 & Mean $=0$ & $\mathrm{y}$ \\
\hline & Point control & 0.49 & 0.4 & 0.11 & Mean $<0$ & $\mathrm{y}$ \\
\hline \multirow[t]{5}{*}{5 years, 10 projects } & Habitat enhance & 0.59 & 0.38 & 0.04 & Mean $=0$ & $\mathrm{n}$ \\
\hline & Habitat establish & 0.61 & 0.36 & 0.04 & Mean $=0$ & $\mathrm{n}$ \\
\hline & Habitat protect & 0.58 & 0.32 & 0.1 & Mean $<0$ & $\mathrm{y}$ \\
\hline & Nonpoint control & 0.59 & 0.37 & 0.04 & Mean $<0$ & $\mathrm{y}$ \\
\hline & Point control & 0.57 & 0.31 & 0.12 & Mean $<0$ & $\mathrm{y}$ \\
\hline \multirow[t]{5}{*}{10 years, 5 projects } & Habitat enhance & 0.82 & 0.17 & 0 & Mean $=0$ & $\mathrm{n}$ \\
\hline & Habitat establish & 0.82 & 0.18 & 0 & Mean $=0$ & $\mathrm{n}$ \\
\hline & Habitat protect & 0.79 & 0.18 & 0.04 & Mean $<0$ & $\mathrm{y}$ \\
\hline & Nonpoint control & 0.81 & 0.18 & 0.01 & Mean $=0$ & $\mathrm{n}$ \\
\hline & Point control & 0.75 & 0.22 & 0.03 & Mean $<0$ & $\mathrm{y}$ \\
\hline \multirow[t]{5}{*}{10 years, 10 projects } & Habitat enhance & 0.92 & 0.08 & 0 & Mean $=0$ & $\mathrm{n}$ \\
\hline & Habitat establish & 0.94 & 0.06 & 0 & Mean $<0$ & $\mathrm{y}$ \\
\hline & Habitat protect & 0.83 & 0.14 & 0.02 & Mean $<0$ & $\mathrm{y}$ \\
\hline & Nonpoint control & 0.94 & 0.06 & 0 & Mean $<0$ & $\mathrm{y}$ \\
\hline & Point control & 0.87 & 0.12 & 0.01 & Mean $<0$ & $\mathrm{y}$ \\
\hline
\end{tabular}

The columns "mean $<0$," "mean $=0$," and "mean $>0$ " show the proportion of results for 1000 simulations of random dates and locations where the estimated effect had an overall decrease in observed chlorophyll-a (mean < 0 ), no change $($ mean $=0)$, or increase in chlorophyll-a (mean $>0)$. The actual estimate of the association with chlorophyll-a change from observed data for restoration projects is also shown. The agreement column shows whether the actual estimate is in agreement (y, yes; $n, n o)$ with the most frequently observed result from the random simulations (italics) the result of using relatively small windows and project combinations, i.e., slicing the data too thin to detect the long-term decline in chlorophyll-a.

The "Actual" and "Agreement" columns in Table 3 indicate the estimated changes for each project using the actual restoration dates/locations and if the result agrees with those from the random simulations. In support of the alternative hypothesis, nine of the rows in the "Agreement" column indicate a result different than a consistent decline in chlorophyll-a expected under the null hypothesis. Compared to random simulations, different results were more often observed for habitat enhancement and habitat establishment projects, where the simulated results most often suggested a decrease and the actual results suggested no change in chlorophyll-a. Nonpoint and point source control projects were in agreement with simulated results, although this does not provide sufficient evidence that the results from the actual data are incorrect. Because the null hypothesis under randomization suggests projects will be associated with water quality improvements based on the independent chlorophyll-a time series, an observed decline in chlorophyll-a in relation to actual restoration projects could still suggest a signal rather than a false positive result. There is no way of identifying type I errors with the current dataset, although the differences from the null results for habitat enhancement and establishment projects do suggest the framework is robust.

\section{Discussion}

A long-term record of restoration activities and water quality data in Tampa Bay provided the foundation to develop a novel decision support tool for coastal restoration practitioners and managers. Consistent with our objectives, this new tool (1) provides a unique process to understand the associations between past restoration projects and known changes in water quality and (2) establishes, under certain assumptions, an expectation of water quality improvements that could result from future restoration activities contingent upon the level of investments in different activities and the necessary time to monitor any observed downstream water quality benefits at local to watershed scales. Overall, we demonstrated a baywide association of water quality changes to different restoration activities that varied by project type, while refining parameters for estimating the results, including the spatial context of interpretation. The flexibility of our approach has potentially 
broad application and extension within the Gulf Coast restoration and management community.

The results support several conclusions that are consistent with recognized, long-term changes in water quality in Tampa Bay. Water infrastructure projects related to point and nonpoint source controls were consistently associated with improved water quality. The record of restoration projects included key point source nutrient controls that occurred primarily in upper Tampa Bay (Hillsborough Bay) and that were successful in reducing nutrient loads during the first two decades of observation (Johansson 1991; Johansson and Lewis 1992; Greening et al. 2014). These outcomes were expected and the ability of the results to clearly demonstrate these longterm associations provided a proof of concept for the overall approach. Moreover, efforts focused on mitigating the effects of nonpoint sources of pollution were more common in the latter half of the record after 1990, and our results provide evidence that these projects have been effective in improving water quality baywide as well. Nonpoint source control efforts broadly described several activities that included, among others, street sweeping, education/outreach efforts, and various best management practices for stormwater, agricultural, and wetland management programs. The ability to document the effects of nonpoint control efforts on water quality relative to end-of-pipe controls is challenging (Hassett et al. 2005; Meals et al. 2010; Liang et al. 2019), and the results suggest that our approach is capable of detecting improvements in water quality from these projects when many are implemented.

Habitat restoration projects were also associated with reductions in chlorophyll-a, although to a lesser magnitude than water infrastructure projects. Our categorization of habitat projects as enhancement, establishment, and protection was developed to better understand potential effects on water quality related to the type and intensity of actions for each group. Specifically, the categories represented extremes from low to high intensity effort, where protection was low effort (e.g., direct land acquisition), establishment was highest effort (e.g., mangrove/seagrass plantings, creation of oyster reefs), and enhancement was moderate effort depending on the activity (e.g., hydrologic restoration for wetlands, exotic species control). Categorization by effort combined with the associated estimates of water quality improvements provides a coarse evaluation of the tradeoffs associated with each project type. For example, habitat protection was consistently linked to chlorophyll-a reductions independent of year windows and number of projects. The effort for land acquisition is minimal relative to the other habitat restoration projects. Conversely, habitat enhancement was not strongly associated with baywide improvements in water quality, and such projects may require more intensive effort and monitoring assessments to understand and contribute toward downstream water quality benefits. Based on these results, habitat protection may be a more immediate and efficient approach than other types of habitat restoration projects, especially if the primary restoration objective is to quickly improve downstream water quality.

Our results also provide an approach to identify an expected range of time and number of projects that are associated with potential improvements in water quality (Diefenderfer et al. 2011). This information was included as an explicit component in Eq. (1) to quantify tradeoffs for different restoration activities based on how results varied by time and effort, similar to the categorization for habitat projects. Monitoring water quality improvements after a short period of time since project completion and with fewer projects (e.g., 5 -year window, 5 closest projects) may be more efficient than those where improvements are observed after longer periods of time and with more projects (e.g., 10-year window, 10 closest projects), dependent on the project type. Given this logic, both habitat protection and point source controls could potentially provide the greatest measured water quality benefits for the least effort, whereas other projects provide lesser improvements, require more time to confer water quality benefits (e.g., full maturation of a habitat enhancement/establishment site), and require more projects to be implemented to contribute to significant water quality improvements (e.g., implementing many nonpoint source controls across a watershed). However, this approach assumes that immediate downstream water quality improvements with minimal effort are the primary restoration objectives, and implicitly discounts the long-term effects that may or may not persist for a given project type or regional restoration challenges. Protection may also be costly in developed areas with competing land use interests, despite minimal restoration requirements. Likewise, other restoration objectives may be a primary driver for pursuing a particular project type (e.g., increasing biodiversity, improving fish and wildlife habitats, etc.).

Conclusions from our approach may also be sensitive to system hysteresis. An initial improvement of water quality associated with a particular project may be obfuscated by chronic degraded conditions, if additional restoration projects that directly address the underlying problem are not pursued (i.e., Scheffer et al. 1998; Borja et al. 2010). As an example, habitat enhancement projects were associated with improvements in Lower Tampa Bay only during the 5-year window when 10 projects were implemented; reductions in chlorophyll-a were not shown to persist at the 10-year window.

\section{Analysis Limitations}

There are several limitations of our approach that affect the interpretation of the results. These assumptions and limitations are a reflection of (1) the inherent uncertainty in quantifying baywide effects of restoration projects that vary considerably in mechanisms affecting water quality (e.g., Baird 2005; Borja 
et al. 2010) and (2) explicit construction of the approach to best account for this uncertainty. Because we do not know the true effect of restoration projects, the results can be interpreted as worst- or best-case descriptions depending on how much certainty is reflected in the estimates. At worst, we provide an approach that can identify the closest restoration projects that have occurred near a water quality monitoring site and a means to compare water quality between project types. We consider this valuable information for managers even if there is considerable uncertainty in the estimates of change; there are currently no tools that match restoration projects to water quality records in Tampa Bay. At best, we provide a decision support tool that provides managers with an expectation of water quality benefits associated with restorations actions and an estimate of time required for improvements to be observed (Diefenderfer et al. 2011). Both kinds of information are critical to inform and sustain environmental restoration programs.

The value of our approach to quantify cumulative effects of restoration activities on improving water quality is likely between the worst- and best-case scenarios outlined above given the confidence that can be invested in the conclusions. The ability of our model to support previously and well-described changes in water quality in response to key management interventions (e.g., improvements from point source controls; Greening et al. 2014; Beck and Hagy 2015) provides additional assurance and weight of evidence that our approach improves our understanding of restoration effectiveness beyond basic relationships presented in Fig. 6. The latter was specifically presented to demonstrate limitations of simpler analysis methods. For example, the separate effects of habitat establishment and point source projects on chlorophyll-a reductions cannot be separated through simple linear analyses because both increase over time, i.e., an association of chlorophyll-a with one project type could be an artifact of an association with another project type. Likewise, a weak association (e.g., habitat protection and chlorophyll-a) does not provide strong evidence that a particular project type is unimportant for water quality improvements, given that the simple analysis may lack sufficient power to detect an association. Operating under these constraints, an explanation of how the new approach can guide management is required to minimize extrapolation of conclusions beyond a reasonable level of confidence in what is provided by the results (i.e., a levels-of-evidence reasoning; Diefenderfer et al. 2011).

As an example, a practitioner could use the following logic derived from our approach to guide future restoration efforts. Figure 7 suggests that point source controls were responsible for an approximate baywide chlorophyll-a reduction of $2 \mu \mathrm{g} / \mathrm{L}$. These results were observed at the 10 -year window and 5 (and 10) closest project combinations. What exactly does this information suggest and what expectations can be derived regarding the likely effects of future point source control efforts? First, an inaccurate conclusion is that baywide chlorophyll-a would be reduced by $2 \mu \mathrm{g} / \mathrm{L}$ after 10 years, if five projects are implemented in the future. A more correct interpretation is that, historically, the aggregate effect of point source control projects for a "typical" station at any point in the record and location in the Bay has been a reduction of $2 \mu \mathrm{g} / \mathrm{L}$ after about 10 years in response to $5-10$ projects, all of which were completed at different times. Importantly, this latter interpretation assumes causal relationships between the projects and changes in chlorophyll-a. This description is also understandably vague, but it provides context of an expectation relative to other types of projects, particularly in narrative terms. For example, the aggregate effects of habitat establishment projects were most apparent for the 10-year window, 10 closest projects combination. With this information, qualitative conclusions about the relative effects of point source control versus habitat establishment can be made. Point source control projects are "more effective" in improving downstream water quality because improvements are expected "quicker" and with "fewer" implemented projects, as applied to a "typical" water quality station that could be at any location in the Bay. Similar but alternative conclusions could be made in different spatial contexts (e.g., "typical" stations in Hillsborough Bay, Table 2).

The flexibility and simplicity of the approach to quantify associations between restoration projects and water quality was purposeful given the constraints of the data. Although the compiled restoration databases included additional information on effort (e.g., acreage restored), these data were not consistently collected and our approach was constrained to the most basic information about each project (i.e., type, completion date, and location). Explicit monitoring of project effectiveness pre- and post-completion is atypical (Neckles et al. 2002; NASEM 2017), and our minimal dataset describing the when and where for each project is a more available description of restoration effort across systems, especially in historic contexts. Within these constraints, the model was strictly associative and any conclusions do not provide a mechanistic explanation. These limitations in our associative approach were apparent in some of the results. Specifically, significant increases in chlorophyll-a associated with particular projects and year/site combinations were observed (e.g., Fig. 7d, three sites for habitat enhancement). These trends are contrary to expectations and highlight shortcomings where the simple design may not have adequately accounted for improvements in downstream water quality (e.g., full ecosystem maturation of a restoration site). Our aggregated estimates using all stations to describe a baywide association were partly meant to reduce the influence of some of these spurious results.

The simplicity of our approach also means that it is highly adaptable to novel contexts. A primary goal of this study was to develop a decision support tool that could be applied elsewhere. We used Tampa Bay as an example where the outcome 
was partially known and a rich dataset was available, affording us a prior expectation of the results. Application to additional systems would require, at minimum, water quality observations spanning multiple years and a similar dataset of completed restoration projects. Our categorization that described relevant water- and habitat-related restoration projects was specific to Tampa Bay, but our approach can include different project definitions and specificity depending on the types of activities that may have occurred and their expected benefits to water quality in a different system. Similarly, the flexibility of our approach to accommodate different year windows and number of projects provides a diagnostic that is sensitive to both the restoration effort expressed in a dataset and how the potential associations could be interpreted. Lastly, we demonstrated flexibility in the spatial context from estimated changes at discrete locations to entire system-wide responses. Although there is uncertainty associated with these interpretations (noted above), the ability to accommodate different spatial contexts means the approach can be readily applied to different systems or management questions at various scales - from a single monitoring station to a regional monitoring network.

\section{Future Directions}

Our approach is not without limitations and future research could build on the methods to provide an improved assessment of restoration effectiveness. Our geospatial analyses were relatively simple, in that spatial matchings were accomplished through Euclidean distances. Alternative distance measures could be used that consider hydrologic distances following flow networks in the watershed. The importance of these approaches could provide insight into pollutant dispersal pathways in environments with low elevation gradients, such as Florida. Weighting restoration projects by relative effort could also facilitate an improved assessment of effectiveness, such as considering total restoration area as an important variable to consider for water quality improvements. Some of these data were available in our compiled dataset, although coverage was insufficient for a complete analysis. Finally, the social and human dimensions of different restoration projects were not considered herein but are important factors that can be equally or even more relevant determinants of success that should be considered when weighing restoration options. Future restoration and monitoring activities should adopt a more comprehensive evaluation of success measures that includes and extends beyond water quality changes.

Acknowledgments This manuscript was a direct result of the Open Science for Synthesis (OSS): Gulf Research Program workshop convened by the University of California Santa Barbara, National Center for Ecological Assessment and Synthesis in July 2017. We are greatly indebted to the workshop instructors, particularly Matt Jones, Bryce Mecum, Julien Brun, Chris Lortie, Amber Budden, Leah Wasser, and
Tracy Teal, for inspiring and motivating our use of open science tools in developing this manuscript. We would also like to thank the many TBEP partners and collaborators for their continuing efforts to restore and monitor Tampa Bay. The progress achieved in restoring the Tampa Bay ecosystem over recent decades would not be possible without the collaborative partnerships fostered in the region. Our partners' willingness to adapt and implement innovative monitoring and management actions in response to the ever evolving challenges threatening Tampa Bay is greatly appreciated. We also thank James Hagy, anonymous reviewers, and editors for their thoughtful comments in improving this paper.

Funding Information This project was partially funded through the OSS: Gulf Research Program workshop, EPA Section 320 Grant Funds, and TBEP's local government partners (Hillsborough, Manatee, Pasco, and Pinellas Counties; the Cities of Clearwater, St. Petersburg, and Tampa; Tampa Bay Water; and the Southwest Florida Water Management District) through contributions to the TBEP's operating budget. K. S. Dorans was supported by the National Institute of General Medical Sciences (grant 1P20GM109036-01A1).

Open Access This article is distributed under the terms of the Creative Commons Attribution 4.0 International License (http:// creativecommons.org/licenses/by/4.0/), which permits unrestricted use, distribution, and reproduction in any medium, provided you give appropriate credit to the original author(s) and the source, provide a link to the Creative Commons license, and indicate if changes were made.

\section{References}

Alfredo, K.A., and T.A. Russo. 2017. Urban, agricultural, and environmental protection practices for sustainable water quality. WIREs Water 4 (5): e1229. https://doi.org/10.1002/wat2.1229.

Baird, R.C. 2005. On sustainability, estuaries, and ecosytem restoration: The art of the practical. Restoration Ecology 13 (1): 154-158. https://doi.org/10.1111/j.1526-100X.2005.00019.x.

Bayraktarov, E., M.I. Saunders, S. Abdullah, M. Mills, J. Beher, H.P. Possingham, P.J. Mumby, and C.E. Lovelock. 2016. The cost and feasibility of marine coastal restoration. Ecological Applications 26 (4): 1055-1074. https://doi.org/10.1890/15-1077.

Beck, M.W., and J.D. Hagy III. 2015. Adaptation of a weighted regression approach to evaluate water quality trends in an estuary. Environmental Modelling and Assessment 20 (6): 637-655. https:// doi.org/10.1007/s10666-015-9452-8.

Beck, M.W., J.D. Hagy III, and C. Le. 2018. Quantifying seagrass light requirements using an algorithm to spatially resolve depth of colonization. Estuaries and Coasts 41 (2): 592-610. https://doi.org/10. 1007/s12237-017-0287-1.

Beyer, J., H.C. Trannum, T. Bakke, P.V. Hodson, and T.K. Collier. 2016. Environmental effects of the Deepwater Horizon oil spill: A review. Marine Pollution Bulletin 110 (1): 28-51. https://doi.org/10.1016/j. marpolbul.2016.06.027.

Borja, Á., D.M. Dauer, M. Elliott, and C.A. Simenstad. 2010. Medianand long-term recovery of estuarine and coastal ecosystems: Patterns, rates and restoration effectiveness. Estuaries and Coasts 33 (6): 1249-1260. https://doi.org/10.1007/s12237-010-9347-5.

Borja, Á., G. Chust, J. G. Rodríguez, J. Bald, M. J. Belzunce-Segarra, J. Franco, J. M. Garmendia, et al. 2016. 'The past is the future of the present': Learning from long-time series of marine monitoring. Science of the Total Environment 566-567. Elsevier B.V.: 698711. https://doi.org/10.1016/j.scitotenv.2016.05.111. 
Comp, G. S. 1985. A survey of the distribution and migration of the fishes in Tampa Bay. In Proceedings, Tampa Bay area scientific information symposium, May 1982, ed. S. F. Treat, J. L. Simon, R. R. Lewis III, and R. L. Whitman Jr., 393-425. Minneapolis, Minnesota: Burgess Publishing Co., Inc. https://tbeptech.org/BASIS/BASIS1/ BASIS1.pdf (Accessed June, 2019).

Curriero, F.C. 2006. On the use of non-Euclidean distance measures in geostatistics. Mathematical Geology 38 (8): 907-926. https://doi. org/10.1007/s11004-006-9055-7.

Diefenderfer, H.L., G.E. Johnson, R.M. Thom, K.E. Buenau, L.A. Weitkamp, C.M. Woodley, A.B. Borde, and R.K. Kropp. 2016. Evidence-based evaluation of the cumulative effects of ecosystem restoration. Ecosphere 7 (3): e01242. https://doi.org/10.1002/ecs2. 1242.

Diefenderfer, H.L., K.L. Sobocinski, R.M. Thom, C.W. May, A.B. Borde, S.L. Southard, J. Vavrinec, and N.K. Sather. 2009. Multiscale analysis of restoration priorities for marine shoreline planning. Environmental Management 44 (4): 712-733. https://doi.org/10. 1007/s00267-009-9298-4.

Diefenderfer, H.L., R.M. Thom, G.E. Johnson, J.R. Skalski, K.A. Vogt, B.D. Ebberts, G.C. Roegner, and E.M. Dawley. 2011. A levels-ofevidence approach for assessing cumulative ecosystem response to estuary and river restoration programs. Ecological Restoration 29 (1-2): 111-132. https://doi.org/10.3368/er.29.1-2.111.

Enwright, N.M., K.T. Griffith, and M.J. Osland. 2016. Barriers to and opportunities for landward migration of coastal wetlands with sealevel rise. Frontiers in Ecology and the Environment 14 (6): 307316. https://doi.org/10.1002/fee.1282.

Gardner, B., P.J. Sullivan, and A.J. Lembo. 2011. Predicting stream temperatures: Geostatistical model comparison using alternative distance measures. Canadian Journal of Fisheries and Aquatic Sciences 60 (3): 344-351. https://doi.org/10.1139/f03-025.

GCERC (Gulf Coast Ecosystem Restoration Council). 2013. Comprehensive plan: Restoring the Gulf Coast's ecosystem and economy. https://www.restorethegulf.gov/sites/default/files/Initial\% 20Comprehensive\%20Plan\%20Aug\%202013.pdf. (Accessed January, 2018).

GCERC (Gulf Coast Ecosystem Restoration Council). 2016. Comprehensive plan: Update 2016, restoring the Gulf Coast's ecosystem and economy. https://www.restorethegulf.gov/sites/default/ files/COL_20161208_CompPlanUpdate_English.pdf. (Accessed January, 2018).

GMFMC (Gulf of Mexico Fishery Management Council). 2017. State management program for recreational red snapper summary: Draft amendment to the fishery management plan for the reef fish resources of the Gulf of Mexico. http://gulfcouncil.org/wp-content/ uploads/B-7-a-Recreational-State-Management-for-Red-Snapper. pdf. (Accessed January, 2018).

Greening, H.S., and A. Janicki. 2006. Toward reversal of eutrophic conditions in a subtrophical estuary: Water quality and seagrass response to nitrogen loading reductions in Tampa Bay, Florida, USA. Environmental Management 38 (2): 163-178.

Greening, H.S., P. Doering, and C. Corbett. 2006. Hurricane impacts on coastal ecosystems. Estuaries and Coasts 29 (6): 877-879. https:// doi.org/10.1007/BF02798646.

Greening, H.S., A. Janicki, E.T. Sherwood, R. Pribble, and J.O.R. Johansson. 2014. Ecosystem responses to long-term nutrient management in an urban estuary: Tampa Bay, Florida, USA. Estuarine, Coastal and Shelf Science 151: A1-A16. https://doi.org/10.1016/j. ecss.2014.10.003.

Gross, C., and J.D. Hagy III. 2017. Attributes of successful actions to restore lakes and estuaries degraded by nutrient pollution. Journal of Environmental Management 187: 122-136. https://doi.org/10.1016/ j.jenvman.2016.11.018.

Hassett, B., M. Palmer, E. Bernhardt, S. Smith, J. Carr, and D. Hart. 2005. Restoring watersheds project by project: Trends in Chesapeake Bay tributary restoration. Frontiers in Ecology and the Environment 3 (5): 259-267. https://doi.org/10.1890/1540-9295(2005)003[0259: RWPBPT]2.0.CO;2.

Hobbs, R.J., and J.A. Harris. 2001. Restoration ecology: Repairing the Earth's ecosystems in the new millennium. Restoration Ecology 9 (2): 239-246. https://doi.org/10.1046/j.1526-100x.2001. $009002239 \mathrm{x}$.

Janicki, A., D. Wade, and J. R. Pribble. 1999. Development of a process to track the status of chlorophyll and light attenuation to support seagrass restoration goals in Tampa Bay. 04-00. St. Petersburg, Florida: Tampa Bay National Estuary Program. https://tbeptech. org/TBEP_TECH_PUBS/2000/TBEP_04_00Chlor-A.pdf (Accessed June, 2019).

Johansson, J. O. R. 1991. Long-term trends of nitrogen loading, water quality and biological indicators in Hillsborough Bay, Florida. Edited by S. F. Treat and P. A. Clark. Tampa, Florida, USA: $2^{\text {nd }}$ Tampa Bay BASIS Proceedings: 157-176. https://www.tbeptech. org/BASIS/BASIS2/BASIS2.pdf. (Accessed June 2019).

Johansson, J. O. R., and R. R. Lewis III. 1992. Recent improvements in water quality and biological indicators in Hillsborough Bay, a highly impacted subdivision of Tampa Bay, Florida, USA. Marine Coastal Eutrophication. Proceedings of an International Conference, Bologna, Italy, 21-24 March 1990: 1199-1215.

Lewis, R.R., P.A. Clark, W.K. Fehring, H.S. Greening, R.O. Johansson, and R.T. Paul. 1998. The rehabilitation of Tampa Bay Estuary, Florida, USA, as an example of successful integrated coastal management. Marine Pollution Bulletin 37 (8-12): 468-473. https://doi. org/10.1016/S0025-326X(99)00139-3.

Liang, D., L.A. Harris, J.M. Testa, V. Lyubchich, and S. Filoso. 2019. Detection of the effects of stormwater control measures in streams using a Bayesian BACI power analysis. Science of the Total Environment 661: 386-392. https://doi.org/10.1016/j.scitotenv. 2019.01.125.

Lombardo, R., and R. R. Lewis III. 1985. A review of commercial fisheries data: Tampa Bay, Florida. In Proceedings, Tampa Bay area scientific information symposium, May 1982, ed. S. F. Treat, J. L. Simon, R. R. Lewis III, and R. L. Whitman Jr., 614-634. Minneapolis, Minnesota: Burgess Publishing Co., Inc. https:// tbeptech.org/BASIS/BASIS1/BASIS1.pdf. (Accessed June, 2019).

Meals, D.W., S.A. Dressing, and T.E. Davenport. 2010. Lag time in water quality response to best management practices: A review. Journal of Environmental Quality 39 (1): 85-96. https://doi.org/10.2134/ jeq2009.0108.

Morrison, G., E.T. Sherwood, R. Boler, and J. Barron. 2006. Variations in water clarity and chlorophylla in Tampa Bay, Florida, in response to annual rainfall, 1985-2004. Estuaries and Coasts 29 (6): 926-931.

NASEM (National Academies of Sciences, Engineering, and Medicine). 2017. Effective monitoring to evaluate ecological restoration in the Gulf of Mexico. Washington, DC: The National Academies Press. https://doi.org/10.17226/23476.

Neckles, H.A., M. Dionne, D.M. Burdick, C.T. Roman, R. Buchsbaum, and E. Hutchins. 2002. A monitoring protocol to assess tidal restoration of salt marshes on local and regional scales. Restoration Ecology 10 (3): 556-563. https://doi.org/10.1046/j.1526-100X. 2002.02033.x.

NRDA (Deepwater Horizon Natural Resource Damage Assessment Trustees). 2016. Deepwater Horizon oil spill: Final programmatic damage assessment and restoration plan and final programmatic environmental impact statement. http://www.gulfspillrestoration. noaa.gov/restoration-planning/gulf-plan. (Accessed June, 2018).

Poe, A., K. Hackett, S. Janicki, R. Pribble, and A. Janicki. 2005. Estimates of total nitrogen, total phosphorus, total suspended solids, and biochemical oxygen demand loadings to Tampa Bay, Florida: 1999-2003. \#02-05. St. Petersburg, Florida, USA: Tampa Bay Estuary Program. https://tbeptech.org/TBEP TECH PUBS/2005/ TBEP_02_05Loadings99_03.pdf. (Accessed June, 2019). 
Rabotyagov, S.S., C.L. Kling, P.W. Gassman, N.N. Rabalais, and R.E. Turner. 2014. The economics of dead zones: Causes, impacts, policy challenges, and a model of the Gulf of Mexico hypoxic zone. Review of Environmental Economics and Policy 8 (1): 58-79. https://doi.org/10.1093/reep/ret024.

RDCT (R Development Core Team). 2018. R: A language and environment for statistical computing, v3.5.1. R Foundation for Statistical Computing, Vienna, Austria. http://www.R-project.org

Ruiz-Jaen, M.C., and T.M. Aide. 2005. Restoration success: How is it being measured? Restoration Ecology 13 (3): 569-577. https://doi. org/10.1111/j.1526-100X.2005.00072.x.

Scheffer, M., S. Carpenter, J.A. Foley, C. Folkes, and B. Walker. 1998. Catastrophic shifts in ecosystems. Nature 413: 591-596.

Schiff, K., P.R. Trowbridge, E.T. Sherwood, P. Tango, and R.A. Batiuk. 2016. Regional monitoring programs in the United States: Synthesis of four case studies from Pacific, Atlantic, and Gulf Coasts. Regional Studies in Marine Science 4: A1-A7. https://doi.org/10. 1016/j.rsma.2015.11.007.

Sherwood, E.T., H.S. Greening, A.J. Janicki, and D.J. Karlen. 2016. Tampa Bay estuary: Monitoring long-term recovery through regional partnerships. Regional Studies in Marine Science 4: 1-11. https:// doi.org/10.1016/j.rsma.2015.05.005.

Sherwood, E.T., H.S. Greening, J.O.R. Johansson, K. Kaufman, and G. Raulerson. 2017. Tampa Bay (Florida, USA): Documenting seagrass recovery since the 1980 s and reviewing the benefits. Southeastern Geographer 57 (3): 294-319. https://doi.org/10. 1353/sgo.2017.0026.

Van Sickle, J., and C.B. Johnson. 2008. Parametric distance weighting of landscape influence on streams. Landscape Ecology 23 (4): 427 438. https://doi.org/10.1007/s10980-008-9200-4.
SWFWMD (Southwest Florida Water Management District). 2018. Southwest Florida Water Management District Geospatial Open Data Portal. https://data-swfwmd.opendata.arcgis.com/. (Accessed January, 2018)

TBEP (Tampa Bay Estuary Program). 2017. Tampa Bay water atlas. http://www.tampabay.wateratlas.usf.edu/. (Accessed July, 2017).

Thom, R.M., G.D. Williams, N.R. Evans, and E. Haas. 2011. Lower Columbia River and estuary habitat restoration prioritization framework. Ecological Restoration 29 (1-2): 94-110. https://doi.org/10. 3368/er.29.1-2.94.

Wang, P.F., J. Martin, and G. Morrison. 1999. Water quality and eutrophication in Tampa Bay, Florida. Estuarine, Coastal and Shelf Science 49 (1): 1-20.

Wortley, L., J.M. Hero, and M. Howes. 2013. Evaluating ecological restoration success: A review of the literature. Restoration Ecology 21 (5): 537-543. https://doi.org/10.1111/rec.12028.

Zedler, J.B. 2007. Success: An unclear, subjective descriptor of restoration outcomes. Ecological Restoration 25 (3): 162-168. https://doi. org/10.3368/er.25.3.162.

Supplement Data analysis frameworks, analysis code, and manuscript source materials are available at https://doi.org/10.5281/zenodo. 3243530. An interactive application exploring results for Tampa Bay and individual Bay segments is available at https://shiny.tbeptech.org/ restoreTB/ind eval.Rmd. 